\title{
Voix et images du pays
}

voix et images

du pays

\section{La Relève : une idéologie des années 1930}

\section{Jacques Pelletier}

Volume 5, numéro 1, 1972

URI : https://id.erudit.org/iderudit/600248ar

DOI : https://doi.org/10.7202/600248ar

Aller au sommaire du numéro

Éditeur(s)

Les Presses de l'Université du Québec

ISSN

0318-921X (imprimé)

1918-5499 (numérique)

Découvrir la revue

Citer cet article

Pelletier, J. (1972). La Relève : une idéologie des années 1930. Voix et images du pays, 5(1), 69-139. https://doi.org/10.7202/600248ar d'utilisation que vous pouvez consulter en ligne.

https://apropos.erudit.org/fr/usagers/politique-dutilisation/ 


\section{La Relève : une idéologie des années 1930}

\section{RÉFLEXIONS PRÉLIMINAIRES}

L'histoire des années 1930 au Québec reste encore à écrire. À notre connaissance, il n'existe aucun travail historique d'ensemble sur cette période pourtant cruciale, rien en tout état de cause qui puisse par exemple être considéré comme l'équivalent de l'excellent et discuté ouvrage de Fernand Ouellet, l'Histoire économique et sociale du Québec, 1760-1850 ${ }^{1}$. Le chercheur qui désire obtenir une représentation d'ensemble de cette période est obligé de se reporter à des travaux qui, quoique excellents dans certains cas, ne donnent jamais qu'une image très partielle de la configuration historique de l'époque. Si bien que le chercheur doit en quelque sorte écrire lui-même l'histoire de ces années à partir des divers travaux partiels disponibles ${ }^{2}$. C'est un peu ce que, pour notre part, nous avons dû faire lorsque s'est posé le problème de rattacher la vision du monde exprimée dans la Fides, 1960.

1. Fernand Ouellet, Histoire économique et sociale du Québec, 1760-1850, Montréal,

2. Il pourra notamment se reporter aux travaux de Mason Wade qui consacre deux chapitres de son étude sur les Canadiens français de 1760 à nos jours, traduit de l'anglais par Adrien Venne, Montréal, Le Cercle du livre de France, 1966, aux années de Crise ; à l'étude d'André Raynauld, Croissance et structure économiques de la province de Québec, Québec, ministère de l'Industrie et du Commerce, 1961; à l'étude de Everett C. Hughes, Rencontre de deux mondes; la crise d'industrialisation au Canada français, traduit de l'anglais par Jean-Charles Falardeau, Montréal, Parizeau, s.d.; à l'analyse impitoyable de Victor Barbeau, Mesure de notre taille, publiée par le Devoir en 1936; à l'Histoire de la province de Québec de Robert Rumilly; enfin à des ouvrages comme celui de Maxime Raymond, Politique en ligne droite, Montréal, Editions du Mont-Royal, s.d., ou celui d'Hector Grenon, Notre peuple découvre le sport de la politique, Montréal, Éditions de l'Homme, 1967, dans lesquels il trouvera quelques renseignements utiles. 
Relève au groupe social qui, dans la société québécoise de cette époque, en constituait le support.

C'est en partie pour combler cette lacune que nous avons décidé de prendre comme objet d'analyse la revue la Relève. Nous avons pensé que des analyses comme celle-ci pouvaient apporter une contribution intéressante à l'histoire des années 1930 et, par ressaut, à l'histoire globale de cette période. Car il n'y a pas au sens strict d'histoire immanente des idées. On peut, il est vrai, pour des fins d'analyse, considérer l'histoire des idées comme un univers autonome, fermé, possédant ses propres principes d'évolution, mais cette façon de voir ne pourra jamais être autre chose qu'une feinte provisoire et lorsqu'on voudra comprendre en profondeur l'histoire des idées, on devra rattacher cette histoire à l'histoire générale des hommes qui lui donne son sens. Il va sans dire qu'on ne pourra dégager un « état d'esprit 1930 » qu'à la suite de nombreuses études comme celle-ci qui devront porter sur les autres mouvements d'idées qu'on pouvait à l'époque observer au Québec. C'est ainsi qu'il faudra que d'autres revues dont la revue Vivre, animée par Jean-Louis Gagnon, la revue les Idées, dirigée par Albert Pelletier, qui réunissait des collaborateurs appartenant à la génération précédant celle de la Relève, les Cahiers de l'École sociale populaire publiés par les jésuites, la revue l'Action nationale, les Semaines sociales du Canada, pour ne nommer que les principales, soient étudiées et que des comparaisons soient faites des résultats de ces études de sorte qu'un « état d'esprit 1930 » puisse être dégagé.

C'est à une telle entreprise que s'est employé un jeune historien français, Jean-Louis Loubet Del Bayle dans un remarquable ouvrage ${ }^{3}$ sur les Non-conformistes des années 30. Å partir de l'étude de trois mouvements de jeunes intellectuels français non encadrés dans les partis politiques traditionnels de ce pays, soit les mouvements Jeune Droite, l'Ordre nouveau et Esprit, Del Bayle a essayé de reconstituer «l'esprit 1930 ». Et il a effectivement réussi à dégager une vision commune à ces trois mouvements qui, sur certains problèmes, n'étaient pourtant pas toujours d'accord. Ce faisant, Del Bayle projette une lumière nouvelle sur l'histoire de cette décade dont la connaissance s'enrichit d'autant. Et il nous indique une voie de recherche prometteuse.

L'étude de la Relève, dans cette perspective, se présente comme un jalon d'une entreprise plus globale.

3. Jean-Louis Loubet Del Bayle, les Non-conformistes des années 30, Une tentative de renouvellement de la pensée politique française, Paris, Seuil, 1969, 496 pages. 
La revue fut fondée en mars 1934 par un groupe de jeunes gens qui, pour la plupart, avaient été formés par les jésuites, au Collège Sainte-Marie. On verra plus loin comment cette formation aura une influence décisive sur l'orientation de leur réflexion. Pour le moment, contentons-nous d'enregistrer le fait. Durant toute l'existence de la revue, le noyau initial des fondateurs demeurera à peu près le même. Le seul changement important à ce niveau sera le départ de Paul Beaulieu en décembre 1943. Les deux autres principaux animateurs de la revue, Robert Charbonneau et Claude Hurtubise, demeureront au poste jusqu'à la toute fin de l'entreprise, en septembre 1948. La revue aura donc duré quatorze ans. Durant ces quatorze années, elle aura publié un total de 103 numéros, dont les 48 premiers sous le nom de la Relève et les 55 autres sous celui de la Nouvelle Relève. Notons cependant que si les numéros de la première série comptaient en moyenne 36 pages, ceux de la seconde comptaient 64 pages et même durant deux années, lorsque le format de la revue sera réduit, jusqu'à 80-85 pages. Les principaux collaborateurs de la revue durant la première série seront Robert Élie, Roger Duhamel, Saint-Denys Garneau, Jean LeMoyne, en ce qui concerne les Québécois, Daniel-Rops, Jacques Maritain, Emmanuel Mounier, en ce qui regarde l'apport de l'étranger. Dans la seconde série, il y aura éclipse de certains collaborateurs québécois, notamment de Paul Beaulieu, Robert Élie, Claude Hurtubise, qui écrivent beaucoup moins régulièrement; par contre, de nouveaux venus deviendront collaborateurs réguliers : Guy Frégault, Berthelot Brunet, Marcel Raymond. Maritain, Daniel-Rops continueront à écrire occasionnellement pour la revue cependant que d'autres collaborateurs français feront leur apparition : Georges Bernanos, Yves R. Simon, Auguste Viatte, Henri Laugier.

Dans le tout premier numéro de la revue, ses directeurs présentaient ainsi leur entreprise : "La Relève est un cahier mensuel fondé par des jeunes. Cette feuille se présente au public, comme la première revue de jeunes qui ne soit ni une affaire de collège, ni le porte-parole des opinions d'un groupe particulier ${ }^{4}$. 》 Pourquoi ces jeunes gens sentaient-ils le besoin d'une telle entreprise ? C'est qu'à leurs yeux un «groupement national catholique indépendant était nécessaire "pour développer dans ce pays un art, une littérature, une pensée dont l'absence commence à nous peser ${ }^{5}$ ». Ce "groupement », il est important de le noter, se voulait d'abord mouvement de pensée. Le vide qu'il se proposait de combler était un vide spirituel. Et c'est ce qu'il continuera d'être tout au long de son existence,

4. La direction, Positions $\$$, la Relève, vol. $1, \mathrm{n}^{\mathrm{0}} 1, \mathrm{p} .1$.

5. Ibid. 
bien qu'il éprouvera parfois, comme nous le verrons par la suite, le besoin d'exercer une action plus concrète, d'ordre social et politique. Mais jamais le "groupement» ne donnera la priorité au politique sur le culturel, comme par exemple l'a fait Parti pris à une époque récente, dont les rédacteurs très jeunes, aussi formés pour la plupart chez les jésuites, étaient pourtant avant tout des «littéraires» comme leurs prédécesseurs de la Relève. Toujours l'activité théorique aura priorité sur la réflexion sociale et politique, et à fortiori, sur l'action sociale et politique. Dès le premier numéro, les directeurs de la revue plaçaient leur entreprise sous le signe du catholicisme à la lumière duquel ils entendaient élaborer une doctrine « tenant compte des diverses tendances modernes, respectant les particularismes de race, mettant également en valeur la personne humaine et la plénitude de la vérité ${ }^{6}$ », et affirmaient leur intention de rendre dans le monde «la primauté au spirituel ${ }^{7} \gg$. Les positions de base de la revue demeureront les mêmes tout au long de son existence. Et ses directeurs seront fondés de reprendre, dans leur présentation de la Nouvelle Relève, un texte de l'article liminaire du premier numéro de la Relève pour montrer que leurs positions de base n'ont pas changé, que leurs recherches s'effectuent toujours à la lumière du catholicisme défini comme le seul «terrain de rencontre » sur lequel puissent être édifiés à la fois une pensée et un ordre temporel concret. Bien sûr, on pourra toujours remarquer quelques changements; par exemple, certains thèmes durant la seconde série seront plus souvent abordés, comme la politique internationale (mais cela était normal puisqu'on était en période de guerre), alors que d'autres seront un peu négligés, par exemple la réflexion sur les problèmes sociaux (qui se posaient par ailleurs avec moins d'acuité que durant la période de la Crise). De même, la revue deviendra-t-elle de plus en plus « littéraire »: elle publiera des contes, de Thériault entre autres, des extraits de romans, de Charbonneau, de Caldwell, etc. Mais cette évolution était prévisible : «le problème social» se posant avec moins d'urgence durant la guerre, il était presque fatal que les collaborateurs de la revue revinssent à leur pente naturelle qui était de s'occuper d'art et de littérature.

Les positions fondamentales de la revue demeurant les mêmes du début à la fin de l'entreprise, il nous semble peu utile d'en faire l'analyse dynamique, ainsi que le propose Gérald Fortin dans un article publié dans Recherches sociographiques en 1963. Comparant l'analyse dynamique de l'idéologie à l'analyse statique, celui-ci expliquait de la façon suivante sa préférence pour la première :

6. La direction, * Positions ^, la Relève, vol. 1 , no 1, p. 2.

7. Ibid. 
L'analyse statique se situe toujours dans un contexte a-temporel ou a-situationnel. Elle ne peut donc saisir la dialectique constante entre les modifications de la situation et les ajustements de l'idéologie. Ces ajustements se traduisent ordinairement par un changement de l'accent placé sur les différents éléments. Ils peuvent aussi se traduire par l'incorporation de nouveaux éléments compatibles ou rendus compatibles avec la structure existante ${ }^{8}$.

Gérald Fortin lui-même, dans sa thèse de doctorat ${ }^{9}$, a ainsi soumis la revue l'Action nationale à une analyse dynamique.

Ce type d'analyse se justifiait alors très bien dans la mesure où Fortin s'était fixé pour objectif d'étudier les relations entre l'évolution interne de la revue d'une part et l'évolution sociale du Québec d'autre part. Il convenait d'autant plus que la période étudiée par Fortin s'étendait sur trente-sept années ; à l'intérieur de cette longue période, celui-ci découpa quatre sous-périodes qui lui servirent de points de repère dans l'étude de l'évolution interne de la revue. Fortin remarqua que cette évolution interne était en corrélation avec l'évolution globale du Québec caractérisée surtout par les processus bien connus de l'industrialisation et de l'urbanisation. En ce qui nous concerne, une étude de cette nature est impossible dans le cas de la Relève. D'abord, parce que cette revue n'a pas eu une existence très longue; ensuite, parce qu'elle n'a guère connu d'évolution importante au cours de son existence. Aussi devons-nous nous résigner à en faire l'analyse statique.

Précisons aussi que notre analyse ne recourt guère aux méthodes quantitatives. Nous n'avons pas jugé bon, ainsi que le fait Fortin dans sa thèse, d'enregistrer la récurrence des thèmes traités par les rédacteurs de la Relève. Cela nous semblait inutile étant donné que notre analyse n'est pas dynamique. Dans une analyse dynamique, un tableau de fréquences peut bien sûr être suggestif encore que sa valeur, si l'on en croit Fortin, est assez relative. Les chiffres, dans l'analyse des idéologies, ne peuvent tout au plus que servir d'indicateurs; en aucun cas, ils ne peuvent remplacer l'analyse qualitative opérée de façon intuitive, avouons-le, par le chercheur. D'ailleurs, il est remarquable que dans les cas que nous connaissons, et nous songeons ici surtout à la thèse de Fortin et dans une moindre

8. Gérald Fortin, *Changements sociaux et transformations idéologiques: deux exemples ", Recherches sociographiques, vol. 4, no 2, 1963, p. 224.

9. Gérald Fortin, An Analysis of the Ideology of a French Canadian Nationalist Magazine, thèse de doctorat présentée à l'Université Cornell en juin 1956, X et 245 pages. 
mesure à celle de Louis Savard ${ }^{10}$, les tableaux sur la récurrence des thèmes ne font que confirmer l'analyse préalablement effectuée de façon intuitive par le chercheur. Dans le cas de la Relève, comme on le verra plus loin, les thèmes que nous avons retenus pour fin d'analyse parce qu'ils nous paraissaient les plus importants étaient aussi quantitativement les plus importants. Il y a donc généralement recoupement entre ce que le chercheur perçoit de façon intuitive et la réalité statistique.

Notre tâche consistera donc à reconstituer la vision du monde qui se dégage de l'analyse de la revue, à montrer comment les prises de position de la revue sur les problèmes politiques, économiques et autres, ses projets de réforme sociale s'enracinent dans cette vision du monde et en sont implicitement la conséquence, et enfin à rattacher cette vision du monde au groupe social qui en constitue le support.

\section{Le problème de la définition de l'idéologie}

Avant de procéder à la reconstitution de la vision du monde véhiculée dans la revue, il nous semble nécessaire de nous attarder quelque peu sur le problème de la définition de l'idéologie.

Nous n'avons pas l'intention de reprendre l'histoire et la pré-histoire du concept d'idéologie. D'ailleurs, celle-ci a déjà été faite et bien faite. On en trouvera, parmi d'autres, une excellente dans un article de Marcel Fournier paru dans le tout premier numéro de la revue Anthropolitique ${ }^{11}$. Nous n'avons pas non plus l'intention d'ouvrir une discussion théorique à ce propos (ce pourrait être l'objet d'une thèse). Nous nous contenterons de rappeler la pensée de quelques auteurs, les plus importants, sur la question, et nous tenterons de préciser l'usage qu'il sera fait de ce concept dans notre travail.

Chez Marx, ainsi que le rappelle Gurvitch ${ }^{12}$, le concept a d'abord une signification très précise : il désigne «les représentations fausses que les hommes se font d'eux-mêmes ». Dans l'idéologie, en effet, ainsi que l'écrit Marx dans

10. Louis Savard, Cité libre et l'idéologie monolithique du vingtième siècle au Canada français, thèse de maîtrise en sociologie présentée à l'Université Laval en avril 1962, 127 pages.

11. Marcel Fournier, "Idéologie et société technique 》, Anthropolitique, vol. 1, no 1, avril 1969 , p. 73-93.

12. Georges Gurvitch, la Sociologie de Karl Marx », la Vocation actuelle de la sociologie, tome II, édition remaniée, p. 285 et sqq. 
l'Idéologie allemande, « les hommes et leurs rapports nous apparaissent placés la tête en bas comme dans une caméra obscure ${ }^{13} \gg$. Pourquoi les hommes se font-ils ainsi des représentations fausses d'eux-mêmes? Parce que ces représentations fausses justifient des positions de classe, servent à camoufler des intérêts que des représentations adéquates de la réalité mettraient à jour. Et ces représentations fausses qui sont le produit de la classe dominante, même les classes dominées, aveugles sur leurs intérêts réels, pourront de bonne foi les partager. Le plus bel exemple de cela nous est offert dans la société moderne par les classes défavorisées qui, bien que privées des avantages concrets de la civilisation dans laquelle elles vivotent, adoptent comme allant de soi des valeurs de cette civilisation qui pourtant expliquent dans une large mesure leur condition de laissés pour compte. C'est que « les pensées de la classe dominante sont aussi, à toutes les époques, les pensées dominantes ${ }^{14} \gg$, et les classes dominées elles-mêmes, se dupant, intériorisent ces pensées sur lesquelles elles règleront leurs comportements.

Ainsi, l'idéologie, à ce stade de la pensée de Marx, désigne non seulement la pensée politique mais encore la pensée sociale et des phénomènes plus larges et à priori moins directement liés à des intérêts, comme la religion par exemple. On sait que pour Marx la religion était un « opium » pour le peuple, c'est-à-dire qu'elle était un aspect de l'idéologie de la classe dominante et, par conséquent, une dimension de l'aliénation du prolétariat. Et dans sa polémique contre Feuerbach, Marx affirme qu'on ne peut débarrasser l'homme de l'aliénation religieuse en s'attaquant de front à la religion, en montrant que c'est une illusion que l'homme lui-même a créée, mais qu'on doit plutôt s'attaquer à la racine de l'illusion qui a sa source dans la contradiction dans les rapports de l'homme avec son milieu. Ce n'est que lorsque cette contradiction sera abolie que l'aliénation religieuse s'évanouira en quelque sorte d'elle-même. Seule une transformation révolutionnaire de la pratique sociale peut déclencher un renversement de la superstructure idéologique.

La notion d'idéologie, par la suite, deviendra chez Marx plus englobante. Seront désignées sous ce terme, rappelle Gurvitch, toutes les sciences humaines et notamment les sciences sociales (à l'exception de l'économie politique marxiste), les programmes des partis politiques, les représentations et opinions, les réactions des différentes classes sociales. Toute science, à l'exception des sciences de la

13. Karl Marx, l'Idéologie allemande, première partie : * Feuerbach *, Paris, Editions sociales, "Classiques du marxisme $» 1968$, p. 36.

14. Ibid., p. 74. 
nature, qui rallient l'unanimité de tous les savants, peu importe leur origine sociale et leur affiliation politique, et de l'économie politique marxiste qui est libérée de tout conditionnement social, étant la science du prolétariat, qui représente lui-même les intérêts de la communauté humaine tout entière, toute science pour Marx est entachée d'idéologie et par conséquent ne mérite pas le statut de science qui lui est généralement accordé.

Enfin, l'idéologie, à partir de la préface de Critique de l'économie politique, prend une signification encore plus étendue. Marx la définit alors de la façon suivante : «Toute œuvre objective de la conscience réelle, individuelle et collective à la fois (langage, droit, morale, art, connaissance) en tant que cette œuvre est en corrélation fonctionnelle avec une classe ou qu'elle participe à la structuration d'une classe ${ }^{15}$. »

Parti d'une définition restreinte de l'idéologie comme technique de justification, d'ordre surtout politique, de la situation qui assure à la classe dominante sa position de contrôle dans la société, Marx a progressivement étendu cette notion à l'ensemble des sciences humaines, à l'exception de l'économie politique marxiste, puis à des phénomènes très généraux comme le droit, la morale, le langage et l'art.

Gurvitch, jugeant que la définition de Marx, étant très extensive, n'est guère opératoire, propose pour sa part de considérer l'idéologie comme un genre particulier de connaissance, «la connaissance politique qui s'affirme dans toutes les structures et dans tous les régimes, mais dont l'importance et le rôle varient ».

Si la définition de Marx est trop extensive, et là-dessus nous sommes d'accord avec Gurvitch, celle de ce dernier ne l'est peut-être pas assez. Car si nous prenons la définition de Gurvitch au sens strict, des phénomènes comme la religion, par exemple, ne pourront pas tomber sous la coupe de l'analyse des idéologies. Or, dans une perspective plus large, si l'on définit l'idéologie à la façon de Fernand Dumont, comme "représentation d'un ensemble social selon une perspective d'action dans et sur la société ${ }^{16} \gg$, le fondement de cette représentation pourra être à caractère religieux ainsi que Dumont l'a montré dans son étude de l'idéologie religieuse de la L. O. C. (Ligue ouvrière catholique) ${ }^{17}$. Les

15. Cité dans Marcel Fournier, op. cit., p. 76.

16. Fernand Dumont, * Structure d'une idéologie religieuse ", Recherches sociographiques, vol. 1, no 2, avril-juin 1960, p. 168.

17. Ibid., p. 161-168. 
définitions de Marx et de Gurvitch nous paraissant respectivement trop extensives et pas assez, c'est dans la direction d'une définition comme celle proposée par Dumont que nous orienterons notre recherche.

En ce qui concerne l'analyse proprement dite des idéologies, la contribution de Marx nous paraît très importante. Celui-ci en effet, dans l'Idéologie allemande, écrit qu'il ne faut pas chercher dans l'idéologie l'image de la réalité mais bien plutôt, à l'inverse, dans la réalité le fondement de l'idéologie, car celle-ci présente une image de la réalité :

A l'encontre de la philosophie allemande qui descend du ciel sur la terre, c'est de la terre au ciel que l'on monte ici. Autrement dit, on ne part pas de ce que les hommes disent, s'imaginent, se représentent, ni non plus de ce qu'ils sont dans les paroles, la pensée, l'imagination et la représentation d'autrui, pour aboutir ensuite aux hommes en chair et en os; non, on part des hommes dans leur activité réelle, c'est à partir de leur processus de vie réel que l'on représente aussi le développement des reflets et des échos idéologiques de ce processus vital ${ }^{18}$.

Si nous voulions appliquer le précepte de Marx rigoureusement, il nous faudrait donc pour notre part commencer notre étude par l'histoire de la Crise, par celle de la classe à laquelle appartenaient les rédacteurs de la Relève pour ensuite, à partir de là, montrer comment la situation de classe de ces jeunes gens a engendré l'idéologie qu'il s'agirait alors de mettre en lumière. Nous avons préféré procéder autrement tout en respectant en définitive le précepte méthodologique de Marx puisque la mise en perspective de la réalité sociale et de l'idéologie sera faite de toute façon dans notre quatrième partie. De Marx, nous retiendrons donc finalement cette règle de méthode qui veut que deux réalités comme une idéologie et la société dont elle est une expression sont dans un rapport dialectique et que l'une et l'autre ne peuvent être comprises que par l'étude de ce rapport.

Mannheim ${ }^{19}$, pour sa part, distingue ce qu'il appelle la conception particulière de la conception totale de l'idéologie. La conception particulière de l'idéologie renvoie aux comportements des individus qui ont tendance (consciemment ou inconsciemment) à se représenter faussement leur situation ou, de façon plus générale, la réalité. Ainsi le mensonge est un déguisement conscient de la réalité alors que l'illusion en est une falsification inconsciente. Mais ce qui intéresse surtout

18. Karl Marx, op. cit., p. 36. 233 pages.

19. Karl Mannheim, Idéologie et utopie, Paris, Librairie Marcel Rivière et Cle, 1956, 
Mannheim, et nous à sa suite, c'est la conception totale de l'idéologie. Mannheim considère alors celle-ci par rapport à de larges groupes historiques (une époque dans son ensemble ou à l'intérieur de celle-ci les vastes ensembles que constituent les classes sociales). L'idéologie dans la conception totale est situationnellement déterminée en ce qu'elle naît dans une conjoncture historique bien précise et répond aux intérêts de catégories sociales déterminées. Par ailleurs, elle est situationnellement transcendante dans la mesure où elle n'est pas une représentation adéquate de la réalité (et l'idéologie n'est jamais une représentation adéquate de la réalité ; lorsqu'elle le devient, elle perd son statut d'idéologie et devient représentation «scientifique » de la réalité). Mannheim introduit alors une nouvelle notion, celle d'utopie, qui se distingue de l'idéologie en ce qu'elle est tournée vers l'abolition du rapport de classes existant, alors que l'idéologie est tournée vers la consolidation du rapport de classes existant. L'utopie, à ce titre, est généralement le fait des classes montantes comme la vision du monde l'est chez Goldmann. L'idéologie serait plutôt l'arme des gens au pouvoir.

Ainsi définie, l'idéologie correspondrait à la deuxième des trois significations que, selon Paul Kahn ${ }^{20}$, ce concept prend chez Mannheim, c'est-à-dire celui de doctrines élaborées pour justifier un système (doctrine qui pourra être de nature juridique, religieuse, politique, etc.). Les deux autres significations du concept chez Mannheim, selon Kahn, sont les suivantes : premièrement, les œuvres objectives de la conscience réelle (c'est-à-dire le langage, le droit, la morale, les systèmes politiques, etc.) ; deuxièmement, les illusions collectives ou représentations fausses que les hommes se font d'eux-mêmes. La notion, dans ces dernières acceptions, prend donc une extension considérable et est un peu l'équivalent de la dernière définition de Marx. On sait que dans ses analyses concrètes Mannheim s'est borné à étudier l'idéologie entendue au sens de doctrine élaborée pour justifier un système. Ses analyses portent toutes en effet sur des mouvements politiques ou para-politiques, qu'il s'agisse des anabaptistes (dont il étudie la pensée de leur principal représentant, Thomas Muntzer), des libéraux humanitaires, des conservateurs allemands du début du XIXe siècle, des socialistes et des communistes contemporains. Ce qui veut dire que dans la pratique il ne s'intéresse à l'idéologie que dans sa définition restreinte et pour autant plus facilement opératoire. Ainsi conçue, la définition de Mannheim se rapproche beaucoup de celle de Dumont ainsi que nous le verrons tantôt.

20. Paul Kahn, Idéologie et sociologie de la connaissance dans l'œuvre de Karl Mannheim », Cahiers internationaux de sociologie, vol. VIII, 1950, p. 147-168. 
Mannheim s'intéresse aussi dans son livre principal, Idéologie et utopie, au problème de la validité de la connaissance. Si toute connaissance, en dernière analyse, exprime le point de vue d'un groupe social particulier, où est la vérité, se demande Mannheim. À cette question, il apporte une double réponse. La connaissance la plus adéquate (et donc la plus « vraie») est celle qui permet la compréhension la plus large de la réalité. Par ailleurs, cette compréhension la plus large, il reviendra généralement aux intellectuels de la fonder à partir de la considération des perspectives partielles présentées par les différents groupes sociaux. Mannheim accorde ainsi un privilège aux intellectuels qu'il estime libres d'attaches sociales. Ce qui est leur faire beaucoup d'honneur, puisqu'on sait très bien que les intellectuels sans attaches sont très rares sinon inexistants. Eux aussi ont des intérêts de groupe à défendre. Quoi qu'il en soit de l'intérêt de cette discussion, nous ne nous y arrêterons pas puisque là n'est pas l'intérêt principal de notre travail. Des thèses de Mannheim, nous retiendrons celle-ci, que l'idéologie (et l'utopie) est situationnellement déterminée et situationnellement transcendante. Ce qui, à y bien penser, confirme et précise la thèse de Marx mais sans, au fond, lui ajouter rien de très substantiel.

Chez Dumont, ainsi que l'a donné à entendre la définition que nous avons citée plus haut, l'idéologie est toujours reliée à l'action. L'idéologie, « représentation d'un ensemble social», est un mode de connaissance pratique, d'abord concernée par l'action. Et elle est non seulement mode de connaissance, mais technique d'action comme le mythe d'ailleurs dont elle tient en quelque sorte lieu dans la société moderne. C'est ainsi que dans un article théorique consacré à l'analyse des idéologies ${ }^{21}$, Dumont écrira qu'à un premier palier « les idéologies apparaîtront comme des axiomatisations symboliques des conditions de l'action », qu'à un second, elles «seront considérées comme la rationalisation d'une vision du monde (ou d'un système de valeurs) prérequise par la culture en question », et qu'à un troisième, elles « apparaissent comme les systèmes symboliques les plus explicites requis par les exigences de l'unanimité sociale devant les situations à définir et les actions à poser ${ }^{22}$ ». L'idéologie est donc tout à la fois : 1 . lecture de la situation ; 2. programme d'action (technique d'existence) ; 3. rationalisation d'une vision du monde dont elle est l'explicitation. Elle se présente comme un texte à déchiffrer, possédant une syntaxe, c'est-à-dire des règles d'organisation

21. Fernand Dumont, «Notes sur l'analyse des idéologies », Recherches sociographiques, vol. $4, \mathrm{n}^{\mathrm{0}} 2$, mai-août 1963 , p. $155-166$.

22. Ibid., p. 162. 
et de fonctionnement propres, et l'explication de son existence ne sera possible que par une confrontation avec la société où elle a pris racine. Car «l'idéologie, écrit Dumont, ajoute des éléments à la structure ; par conséquent, toute recherche de corrélation doit être exclue au départ. Il s'agira de définir les deux termes, non dans leur correspondance, mais dans leur complémentarité, sans préjuger du poids de réalité de l'un et de l'autre ». Pas question donc de retrouver dans l'idéologie l'image de la réalité.

Marcel Fournier, dans son article «Idéologie et société technique », résume dans un schéma très révélateur les conceptions de l'idéologie de Fernand Dumont et de Marcel Rioux qui sont à peu près semblables (c'est pourquoi il peut les résumer dans un schéma unique). Ce schéma, nous le «traduirons » dans les quatre propositions suivantes. Premièrement, l'idéologie est une rationalisation d'une vision du monde. Deuxièmement, l'idéologie exerce une fonction de légitimation de la position des groupes dans la structure sociale. Troisièmement, elle assume à l'égard du groupe lui-même une fonction d'intégration. Quatrièmement, elle appelle à l'action : elle a une valeur de mobilisation.

Fournier, s'inspirant fortement des conceptions Dumont-Rioux, propose la définition suivante de l'idéologie que nous considérons pour notre part très satisfaisante :

L'idéologie est en effet à la fois une théorie, mais particulière puisque sélective (donnant de la réalité une représentation fragmentée) et particularisée (propre à la classe socio-économique dominante ou d'une façon plus générale à tout groupe de dirigeants) et un instrument en tant que légitimation - mobilisation - intégration ${ }^{23}$.

La Relève, qui n'était pas l'organe d'un mouvement social ou politique, n'a donc pas servi, comme idéologie, à légitimer des comportements politiques. En ce sens, elle n'était pas directement liée à l'action immédiate et concrète. Il n'en reste pas moins que comme mouvement de pensée, une importante partie de sa réflexion a été consacrée à l'analyse des conditions et des principes d'une action temporelle efficace. En ce sens, on peut dire qu'elle constitue une idéologie et, par conséquent, qu'elle peut être étudiée comme telle.

L'essentiel de notre travail portera donc sur l'idéologie dans ses dimensions : lecture de la situation et rationalisation d'une vision du monde. Ces deux dimensions sont d'ailleurs liées très intimement dans la mesure où la lecture de

23. Marcel Fournier, op. cit., p. 91. 
la situation s'explique par la vision du monde des «lecteurs en question. Il s'agira donc essentiellement pour nous de voir de quelle façon les rédacteurs de la Relève ont abordé les probièmes auxquels ils ont consacré leur réflexion. Il ne saurait être question par ailleurs d'analyser l'idéologie de la Relève en tant qu'instrument d'argumentation. Les rédacteurs de la revue ne s'étant à peu près jamais définis en fonction de l'événement, leur idéologie ne peut être considérée en tant qu'instrument de légitimation, pour reprendre l'expression de Fournier, et encore moins, bien entendu, comme instrument de mobilisation en vue de l'action.

Adam Schaff, pour sa part, dans un article publié en 1967 dans la revue l'Homme et la société ${ }^{24}$, établissait des distinctions entre ce qu'il appelait les définitions génétique, structurale et fonctionnelle de l'idéologie. À la suite de Schaff, mais en donnant à ses concepts une acception un peu différente, nous dirons qu'effectivement l'idéologie se présente comme une structure, c'est-à-dire un agencement d'éléments intégrés de façon cohérente et reliés fonctionnellement l'un à l'autre, une structure dans laquelle il nous faudra distinguer les éléments constitutifs et montrer comment ils sont reliés l'un à l'autre (c'est ce que nous ferons dans les parties deux et trois), structure dont nous essayerons de retracer la genèse et de mettre en lumière la fonction qu'elle remplissait pour le groupe qui en était le support (ce sera l'objet de notre quatrième partie).

\section{UNE VISION DU MONDE THÉOCENTRIQUE ET HIÉRARCHISÉE}

\section{A. Le concept de vision du monde}

Nous l'avons dit dans notre introduction : l'idéologie est une rationalisation, une explicitation d'une vision du monde. Mais qu'entend-on précisément par cette notion de vision du monde?

Lucien Goldmann, qui en a fait le pivot de ses analyses, notamment dans ses études sur Kant, sur les Pensées de Pascal et sur le théâtre de Racine, en donne la définition suivante : «Nous appelons «vision du monde $\gg$ une perspective cohérente et unitaire sur les relations de l'homme avec ses semblables et avec l'univers ${ }^{25}$. » Précisant sa pensée, Goldmann écrit que la vision du monde n'est

24. Adam Schaff, "la Définition fonctionnelle de l'idéologie et le problème de la fin du siècle de l'idéologie $»$, l'Homme et la société, no 4, avril-juin 1967, p. 49-59.

25. Lucien Goldmann, * Thèses sur l'emploi du concept de vision du monde en histoire de la philosophie », l'Homme et l'histoire, p. 399. 
pas une « réalité empirique donnée », mais « un instrument conceptuei de travail, une extrapolation construite par l'historien, extrapolation qui ne comporte cependant rien d'arbitraire, car elle est fondée sur la structure de la pensée réelle des individus ${ }^{26} \triangleright$. Instrument conceptuel de travail, pour une part, la vision $d u$ monde, bien que réalité construite, n'en constitue pas moins une réalité. Ce n'est pas une pure fabrication, une invention de l'esprit du chercheur, une expression de son imagination débridée. Car aussi bien il la «construit » à partir de l'étude des textes. C'est une réalité construite dans la mesure où elle ne lui est pas donnée d'emblée, où il doit, pour la dégager, interroger et faire parler les textes. En tant qu'instrument de travail, elle se rapproche de la notion de type idéal de Max Weber qui est aussi une construction à partir d'éléments empruntés à la réalité, mais elle s'en distingue en ce qu'elle entend désigner une réalité bien concrète et non sa représentation idéale.

Étudiant les Pensées de Pascal, Goldmann montrera qu'elles expriment une «vision tragique » du monde, vision tragique car partagée entre, d'une part, une exigence de réalisation mondaine des valeurs, un désir d'action sur le monde et, d'autre part, la conviction absolue qu'il est impossible de réaliser les valeurs en ce monde. Le tragique de la vision provient de l'impossibilité de faire la synthèse des deux positions. Or, cette vision du monde, écrit Goldmann, c'est celle-là même d'une fraction de la noblesse de robe non intégrée dans le jansénisme dont les Pensées de Pascal illustrent un courant important. Ainsi donc la vision tragique telle qu'on peut la dégager d'une lecture des Pensées de Pascal trouve-t-elle son explication dans les contradictions d'une fraction de la noblesse de robe. C'est que «les visions du monde sont des faits historiques et sociaux. Elles sont des ensembles de manières de penser, de sentir et d'agir, qui dans certaines conditions s'imposent à des hommes se trouvant dans une situation économique et sociale analogue, c'est-à-dire à certains groupes sociaux ${ }^{27} \gg$. Dans son petit livre Sciences humaines et philosophie, Goldmann précisera que ces groupes sociaux, ce sont les classes sociales, qui constituent «les infrastructures des visions du monde ${ }^{28}$.

Marc-Adélard Tremblay et Paul Charest, pour leur part, dans une perspective anthropologique, définissent dans les termes suivants la vision du monde : «La vision du monde est la conception que se font les membres d'une société

26. Lucien Goldmann, - Thèses sur l'emploi du concept de vision du monde en histoire de la philosophie », p. 399.

27. Ibid., p. 400.

28. Lucien Goldmann, Sciences humaines et philosophie, Paris, Editions Gonthier, * Médiations », 1966, 149 pages. 
d'eux-mêmes, du milieu environnant, de l'univers et de leurs relations avec ce milieu et avec cet univers ${ }^{29}$. 》 Cette définition recoupe d'assez près celle de Goldmann.

La vision du monde est en quelque sorte une attitude première, une prise de position fondamentale à l'endroit de l'univers, de la société et des valeurs, attitude fondamentale qui oriente de façon décisive tous les comportements pratiques de l'homme dans son existence quotidienne, par laquelle s'éclairent ses prises de position sur les problèmes les plus divers qui, à première vue, pourraient sembler discordantes ou totalement incompatibles.

C'est ainsi que la mise à jour de la vision du monde des rédacteurs de la Relève nous permettra (devrait nous permettre) de comprendre leurs prises de position sur les questions intellectuelles, sociales et politiques.

\section{B. La vision du monde des rédacteurs de la Relève}

La vision du monde des rédacteurs de la Relève, on la retrouve tout entière dans un texte extrêmement important, fruit d'un long travail de réflexion portant sur plusieurs mois, publié sous le titre "Préliminaires à un manifeste pour la patrie » dans le numéro de septembre-octobre 1936. Nous aurions pu, bien sûr, pour reconstituer cette vision du monde, recourir à de nombreux textes dispersés un peu partout dans la revue. Mais nous croyons que cela n'aurait rien ajouté de substantiel à notre analyse. Car le texte que nous utiliserons est en quelque sorte une condensation de tous les éléments que nous aurions pu trouver ailleurs dans la revue.

Le texte est d'autant plus important qu'il est signé par les quatre principaux rédacteurs de la revue, Robert Élie, Claude Hurtubise, Paul Beaulieu, Robert Charbonneau, et qu'il constitue à lui seul, à l'exception d'un bref texte d'André Laurendeau, le contenu entier de la revue. Dans toute l'existence de la revue, aucun autre texte n'aura ainsi l'honneur de composer à lui seul tout un numéro. C'est dire son importance.

Les auteurs, dans leurs premiers paragraphes, présentaient leur travail comme des «notes sur le nationalisme», "des exercices, une forme imparfaite qu'a prise notre méditation sur les concepts de patrie, de nation, sur l'indépendance des deux,

29. Paul Charest et Marc-Adélard Tremblay, *Vision du monde à Saint-Augustin *, Recherches sociographiques, vol. 8, no 2, mai-août 1967, p. 151. 
sur la personnalité, l'humanisme et la sainteté ${ }^{30} »$. Le texte se présentait donc comme une réflexion préliminaire, un déblayage théorique préalable à la rédaction d'un «manifeste pour la patrie». Ce manifeste qui devait être publié en 1938 ne le sera jamais. Nous proposerons plus loin une explication de cette lacune. Pour le moment, retenons le fait.

Il s'agit, répétons-le, d'un texte théorique dont l'abord n'est pas toujours facile. En raison, d'une part, du vocabulaire utilisé par les rédacteurs, qui est souvent non seulement abstrait mais imprécis et parfois confus, d'autre part, d'un manque de composition évident. Une lecture attentive nous a néanmoins permis d'en dégager la vision du monde que nous présenterons sous la forme des propositions suivantes :

1. L'homme est un être double, fruit de la réunion d'un corps et d'une âme. L'homme est à la fois un individu, et en tant que tel, ordonné à la cité, au bien commun terrestre, et une personne, c'est-à-dire, «un lieu intérieur où toutes les actions de l'homme prennent valeur pour l'éternité \$ ou si l'on préfère « une nature individuelle ou singulière subsistante et «capable de se posséder elle-même * (Maritain), de posséder hors d'elle-même et pour elle-même, donc qui rapporte les choses à un ciel intérieur où elles se subordonnent à l'essentiel ».

Qu'est-ce que l'essentiel ? C'est la contemplation de Dieu. La personne, dans l'ordre des valeurs, a donc une priorité hiérarchique sur l'individu car \& ce qui se rapporte à l'âme est plus élevé que ce qui concerne le corps ».

2. La société qui a pour fin d'assurer le bien commun temporel doit être organisée de telle façon que l'accomplissement de la fin supra-temporelle de l'homme soit facilité. Car «la nation, comme l'État, et chacun sur son plan particulier, n'a d'autre fin que d'aider au perfectionnement de la personne créée pour Dieu ».

Comme le temporel est subordonné au spirituel, la société civile est subordonnée à la société divine dont elle doit refléter les principes, de sorte que «les lois si relatives de la justice ne peuvent oublier celles, immuables, de la justice divine, et les lois qui veulent une certaine répartition des richesses, celles de la charité ». Et l'État qui oublierait cette subordination naturelle et nécessaire agirait contre les intérêts supérieurs de la personne : "Une cité dont le droit ne se fait que pour permettre premièrement la liberté aux désirs de l'animal, à ses œuvres,

30. Toutes les citations de la Relève dans cette partie, sauf indication contraire, sont tirées du texte a Prélimaire à un manifeste pour la patrie », publié dans le numéro de septembre-octobre 1936. 
un État qui ne censure que ce qui nuit au corps, ne comprend pas la liberté, n'agit aucunement pour la personne. »

Il n'y a donc pas autonomie complète du temporel par rapport au spirituel. On peut même dire qu'il n'y a pas d'autonomie du tout car la société temporelle elle-même doit être un ordre temporel chrétien. Et s'il y a une sphère du temporel distincte de celle du spirituel, c'est qu'elle est exigée par la division sociale du travail, pourrait-on dire.

3. La société civile a pour fin d'assurer le bien commun temporel. Ce bien commun sera assuré par deux sortes d'œuvres:

a) les œuvres actuelles, qui ont pour objet le corps et qui ont « comme but de procurer un certain bien-être nécessaire à d'autres œuvres».

b) les œuvres inactuelles, qui ont pour objet la vie de l'esprit, et qui sont ordonnées au développement de la personne.

Les œuvres actuelles comprennent : i) la politique, qui est la science de l'organisation sociale, qui s'intéresse à l'homme en tant qu'être social ; ii) l'économique, qui s'intéresse à l'homme des besoins et qui est la science de l'organisation économique.

Les œuvres inactuelles comprennent essentiellement l'éducation (creuset de la culture) qui a pour fin de former des personnes. L'éducation fait donc en quelque sorte le pont entre le spirituel et le temporel puisqu'elle doit à la fois former des personnes et des citoyens.

Les œuvres actuelles ont donc pour fin de satisfaire les besoins de l'homme en tant qu'individu alors que les œuvres inactuelles ont pour fin de satisfaire ses besoins en tant que personne. Les œuvres actuelles, bien entendu, sont subordonnées aux œuvres inactuelles et elles «perdront toute valeur en n'étant pas subordonnées aux exigences d'un autre ciel où règne à la place des vérités de l'ordre temporel, la Vérité \$. Car il ne faut jamais oublier que si l'homme fait partie du monde en tant qu'individu, il est aussi hors du monde en tant que personne. Et sa première préoccupation doit être de se développer en tant que personne.

4. La Patrie constitue le cadre dans lequel l'homme pourra le mieux s'accomplir en tant que personne.

Qu'est-ce que la patrie? C'est une donnée qui s'impose à l'évidence de l'homme : « Tout homme a une patrie comme il a un corps et tout homme a des 
devoirs envers cette patrie comme envers ce corps. C'est donné, c'est un fait, un bienfait ; il y a donc là nécessité d'aimer. » La patrie est une réalité charnelle que l'homme découvre peu à peu en vieillissant et dont les frontières changent au fur et à mesure de cette découverte :

L'homme se connaît dans sa patrie, confusément; mais par elle dans ses parents et par l'éducation. La patrie de l'enfant dépasse peu le jardin de la famille ; puis l'église, l'école, le bois s'y ajoutent; des hommes y vivent, animent cette matière, lui donnent un sens. La patrie s'étend à la commune. Par l'histoire, elle déborde sur tout le pays, mais déjà elle est moins concrète : l'idée de nation apparaît ; l'idée de la culture suit par le truchement de la nationalité et de l'éducation.

L'homme doit sa première fidélité à la patrie avant de la devoir à la nation comme nous le verrons tantôt.

De même que le corps de l'homme est subordonné à son esprit, la patrie est subordonnée à l'Église, représentante de Dieu sur terre et « ce ne sera pas elle qui reniera la surnature, qui sacrifiera cette valeur plus universelle qu'est l'Église : l'homme de foi trouve place dans le monde ». Et ailleurs : «Le patriotisme qui ne peut être considéré en dehors de la personne, ne prend son vrai sens et sa vraie valeur que subordonné à un ordre chrétien, ou plus généralement à une notion chrétienne de l'humanisme. » Toujours cette idée de subordination à un ordre éternel des valeurs...

La patrie, avons-nous dit plus haut, constitue le cadre dans lequel l'homme pourra le mieux se réaliser en tant que personne. Pourquoi ? C'est qu'elle est le " moyen humain très grand » dont l'homme dispose pour transformer les nécessités qui pèsent sur lui en agents de libération. Or ces nécessités tiennent à la condition de l'homme, dont l'âme, comme conséquence de son union avec la matière, rencontre, dans son exercice, deux obstacles que les rédacteurs de la Relève désignent ainsi : l'opacité et le mouvement. Autrement dit, et pour ne pas nous perdre dans le jargon des rédacteurs du texte, l'âme traîne un boulet, le corps, qui doit être entretenu, qui a ses exigences et qui absorbe une grande part des énergies de l'homme. Or la patrie est l'instrument tout désigné pour la satisfaction du corps ; ce faisant, elle facilite la vie contemplative de la personne et accomplit ainsi une œuvre hautement méritoire. Ainsi que l'écrivent les rédacteurs du manifeste :

Elle oblige à un ordre où la vie animale et l'éducation peuvent s'accomplir selon la fin dernière de l'homme, et à un ordre humain qui facilite la con- 
quête de la vie contemplative. Elle est dans l'ordre de la nature l'une des valeurs humaines les plus universelles.

5. La patrie, par le travail de ses enfants, donne lieu à une culture. Celle-ci est «synonyme de trésor spirituel ; n'est que l'expression personnelle de la nationalité, d'une race, d'un peuple ». Les cultures sont donc nationales. Et elles se différencient les unes des autres par leurs traditions. Dans cette optique, l'existence de la nation canadienne-française fait problème "parce que nos traditions ne sont pas encore traduites en des œuvres profondes et profondément caractéristiques ». Mais elles ne sont pas pour autant des univers clos. Car la nationalité, mode de penser et d'agir propre à un groupe d'hommes donné, « constitue la détermination qui nous rend accessible l'universel ». C'est pourquoi « un chef-d'œuvre créé par un Allemand est un chef-d'œuvre pour un Français ». La fin de la culture, c'est l'universel, c'est, selon une expression de Maritain, «l'épanouissement de la vie proprement humaine $\gg$.

La nation se distingue de la patrie en ce que ce dernier concept désigne une réalité charnelle alors que le premier désigne une réalité plus complexe, de l'ordre de l'esprit. En ce sens, elle est une réalité hiérarchiquement supérieure (dans l'ordre des valeurs) à la réalité de la patrie.

La nation ne doit pas être confondue avec l'État. Un État peut comprendre plusieurs nations, c'est-à-dire plusieurs centres de culture. Bien sûr, dans la pratique les frontières des nations et des États se confondent souvent mais cela ne change rien au fait qu'il n'y a pas identification forcée entre l'État et la nation.

Toute revendication de la nation ne pourra être faite qu'au nom de la culture. Aussi toute revendication d'autonomie pour le Québec n'aura de valeur que si elle est faite au nom de la culture. Revendiquer l'autonomie pour des raisons politiques ou économiques est absurde. Celles-ci ne pourront être considérées comme valables que s'il est prouvé que le développement de la culture exige l'autonomie politique et économique de la nation.

Enfin, il importe de se rappeler que la nation, comme l'État, n'a « d'autre fin que d'aider au perfectionnement de la personne créée par Dieu ».

6. La nation, si elle n'a pas de mission proprement apostolique, comme l'Église, poursuit quand même "une mission qui lui est départie par la Providence, et c'est dans la mesure où elle est fidèle à cette mission qu'elle accède à une valeur universelle ». La mission qui lui est départie par la Providence, il appartient à chacune des nations d'en comprendre la signification et d'agir en conséquence. 
En résumé, la vision du monde qui se dégage de l'analyse du manifeste est théocentrique et hiérarchisée.

Dieu est au centre de cette vision : le premier devoir de l'homme est de l'adorer et de le servir. La vie contemplative, dans l'ordre des valeurs, est donc plus importante que la vie active. Et cette dernière n'a de valeur que pour autant qu'elle facilite la première.

Dieu n'est pas présent au monde à la façon d'un astre mort : il agit sur le monde par sa Providence. Il est donc doublement présent. Et la société doit être organisée de telle façon qu'elle facilite au maximum à l'homme la tâche d'adorer son Créateur. Aussi la société temporelle ne peut-elle pas affirmer son autonomie par rapport au spirituel. Non seulement elle doit refléter dans son organisation les vertus divines, mais elle doit encore faciliter la pratique de la vie contemplative. De même que le vital (c'est-à-dire les activités ordonnées à la satisfaction des besoins corporels) est subordonné au culturel (aux activités de l'esprit), le culturel est subordonné au spirituel.

Le monde est représenté comme un ordre, une hiérarchie, ou encore un organisme dont Dieu et les valeurs spirituelles formeraient la tête qui ordonne les parties inférieures et à laquelle celles-ci sont ordonnées. Le monde vu par les rédacteurs du manifeste est un monde stable, comportant une hiérarchie rigoureuse et immuable, un monde figé en un équilibre statique, immobilisé en quelque sorte hors du temps et de l'espace dans la sphère abstraite et lointaine des principes qui ont leur assise dans l'éternité. Ce n'est pas pour rien, comme nous le verrons plus loin, que les rédacteurs de la Relève, à la suite de Maritain, désireront l'établissement d'un Nouveau Moyen Âge. C'est que le Moyen Âge était effectivement un monde ordonné, comportant une hiérarchie précise et rigide dans laquelle chacun avait sa place et $\mathrm{y}$ restait, et où Dieu avait la place suprême.

Les prises de position des rédacteurs de la Relève, leurs projets de réforme sociale et économique, leur conception de l'art et de la littérature seront autant de manifestations de leur attitude fondamentale devant le monde. C'est ce que la partie suivante entend examiner à l'aide d'un certain nombre d'exemples concrets.

\section{UNE IDEOLOGIE EN MARGE DU RÉEL}

Nous n'avons pas l'intention d'analyser en profondeur tous les thèmes ou objets de réflexion abordés par les rédacteurs de la Relève. Ce serait là une 
entreprise immense et probablement très fastidieuse à certains moments. Aussi avons-nous décidé d'étudier leur pensée concernant les cinq principales questions sur lesquelles se porta leur attention et de ne consacrer que quelques paragraphes aux questions auxquelles les rédacteurs de la Relève eux-mêmes attachèrent moins d'importance. Cette partie comprendra donc sept sections, une pour chacun des thèmes principaux abordés, plus une pour les autres thèmes et enfin une dernière dans laquelle nous tenterons de faire le point et de rattacher la pensée des rédacteurs de la Relève exposée dans cette partie à la vision du monde dégagée dans la partie précédente.

\section{A. La Crise}

Au moment de la fondation de la Relève, en mars 1934, le Canada français était encore en période de crise économique aiguë. De nombreuses usines continuaient à fermer leurs portes tandis que d'autres ne tournaient plus qu'au ralenti. Des milliers de travailleurs étaient en chômage et leur subsistance ainsi que celle de leurs familles étaient assurées par le secours direct. Dans les villes, la misère était profonde et demeurait un problème social important.

Les rédacteurs de la Relève consacreront plusieurs articles au problème de la Crise. Dès le deuxième numéro de la revue, le Père Doncœur, un conférencier français pour qui les rédacteurs de la Relève avaient beaucoup d'admiration, attirera l'attention, au-delà de la dimension sociale et économique de la Crise, sur sa dimension spirituelle. Pour lui, la Crise était d'abord une crise de civilisation :

D'autre part, parlant ici de la crise mondiale, j'envisage un ensemble de circonstances bien plus vastes que l'on ne pense. Pour l'ordinaire, la crise, c'est la crise économique, crise du commerce, crise de l'industrie, crise de l'exportation, donc crise du travail, chômage et, procédant de tout cela ou au contraire le précédant : crise de la bourse, crise du crédit, crise de l'argent. L'immense angoisse du monde, celle qui occupe les parlements, les conférences, les assemblées de techniciens, celle qui prend à la gorge le pauvre peuple des chômeurs et des marcheurs de la faim, c'est du souci $\mathrm{du}$ pain quotidien en définitive qu'elle prend son caractère tragique. Je suis bien éloigné d'en parler à la légère, car une telle souffrance est en soi un grand mal ; mais elle entraîne bien d'autres conséquences et l'on sent bien que ce sont les bases économiques du monde moderne qui sont ébranlées. J'envisage cependant un horizon encore plus vaste et je donne à ce mot de crise mondiale son sens le plus complet car ce sont toutes les valeurs qui vont être ou qui sont déjà mises en cause. Et non pas seu- 
lement le Nickel, la Steel ou la Bell, mais toutes les valeurs spirituelles sur quoi reposait notre société ; propriété, droit, morale, religion ${ }^{31}$.

La dimension économique de la Crise n'est donc pas niée, mais elle est subordonnée à sa dimension essentielle, qui est spirituelle. La crise économique, dans cette perspective, n'est que la manifestation la plus évidente, la plus spectaculaire, d'une crise plus fondamentale, se situant au niveau des valeurs. Cette idée sera reprise dans un article de Claude Hurtubise qui précisera que la Crise, "manifestée, surtout sur le plan matériel, parce que vécue si cruellement,... n'en garde pas moins son origine et ses éléments de solution sur le plan métaphysique ${ }^{32} \gg$.

Ailleurs, le même Hurtubise ajoutera que la Crise, en dernière analyse, est une conséquence du fait que les hommes n'accordent plus la primauté au spirituel. Nous nous permettrons, malgré sa longueur, de citer en entier le paragraphe qu'Hurtubise consacre au développement de cette idée car il traduit très bien l'attitude profonde des collaborateurs de la Relève devant la Crise :

Je comprends qu'il est difficile d'admettre ce que la querelle des universaux apporte à la solution des problèmes économiques. Mais ce qui est impardonnable, c'est de ne pas voir que le monde crie de misère justement parce qu'il nie cette primauté du spirituel qu'on s'obstine à vouloir mettre en contradiction avec les nécessités de la faim, parce que l'organisation politique et économique du monde n'est pas appuyée sur une philosophie du réel, c'est-à-dire une philosophie qui partant du réel terrestre, remonte aux Réalités supérieures. Impardonnable de croire encore que la politique suffit à l'homme et se suffit à elle-même. La misère n'est pas une question de révolution, mais il faudra beaucoup d'amour de Dieu et des hommes à ceux qui la feront. En définitive, la misère est une question du spirituel ${ }^{33}$.

Le désordre économique témoigne d'un désordre plus profond de la personne. «Le vrai désordre, écrit André Laurendeau, est là. En moi. Il se tapit en mon cœur qu'il étreint. Il se cache dans les replis de mes désirs et de mes ambitions. Je combats à l'extérieur l'ennemi que je nourris en moi ; je sabre les effets et je chéris la cause ${ }^{34}$.» Aussi bien, le désordre ne pourra-t-il trouver de solution véritable qui ne soit d'abord une révolution de la personne. La transformation

31. Paul Doncœur, " la Jeunesse chrétienne dans la crise mondiale », la Relève, vol. 1, $\mathrm{n}^{0} 2$, p. $7-8$.

32. Claude Hurtubise, « Primauté de la souffrance », la Relève, vol. 1, no 7, p. 176.

33. Claude Hurtubise, "la Misère et nous ", la Relève, vol. 2, no 7, p. 201.

34. André Laurendeau, "Préliminaires à l'action nationale *, la Relève, vol. 2, no 1 , p. 35 . 
du monde suivra la transformation de soi. C'est d'abord cette dernière qu'il importe d'effectuer.

Phénomène spirituel, la Crise est l'aboutissant d'une longue histoire, une histoire qui commence, selon le Père Paul Doncœur, à la chute du Moyen Âge, lorsque l'homme a cessé de régler ses conduites d'après la volonté de Dieu et décidé de ne plus se fier qu'à ses propres lumières. L'individualisme, par une pente fatale, devait plonger l'humanité dans la crise actuelle. \& La Renaissance, la Réforme, le libertinage secret du XvII e siècle, public du XVIIIe, la « Philosophie *, les «Lumières », préparant à la Révolution française ${ }^{35}$ », constituèrent autant d'étapes dans la course de l'homme vers l'abîme.

Le christianisme a sa part de responsabilité dans cette triste affaire. S'il avait su réagir à temps contre les méfaits de l'individualisme en se réformant de façon radicale, les hommes auraient continué à s'en inspirer et la Crise aurait pu sans doute être évitée. C'est du moins la thèse que défendra Maritain dans un article sur la nature de la politique :

C'est de nos manquements, de nos complaisances et de nos omissions que les violences et les misères de notre temps nous renvoient durement le visage. Si les chrétiens avaient vécu le christianisme, s'ils avaient pris pleine conscience de leur vocation, je dis à l'égard de l'existence profane elle-même, nous n'en serions pas où nous en sommes, les douleurs du temps ne seraient pas devenues si criantes ${ }^{36}$.

Pour résoudre la Crise, il faudra donc que les chrétiens prennent leurs responsabilités, d'abord en se réformant eux-mêmes, ensuite en aménageant la Cité de telle sorte que les vertus évangéliques de justice et de charité y règnent. Ainsi, la misère pourra-t-elle être combattue par l'établissement d'une justice sociale fondée sur les principes chrétiens.

Ainsi donc la Crise est-elle d'abord perçue comme un problème spirituel plutôt qu'économique et analysée en tant que tel. À aucun moment, dans toute l'histoire de la revue, on ne trouve une analyse économique de la Crise. Aucune étude n'est consacrée à son origine prochaine et à ses conséquences économiques et sociales. Aussi, cette analyse est-elle caractérisée par un haut degré d'abstraction.

À aucun moment non plus les rédacteurs de la revue n'ont proposé de programme concret pour remédier à la Crise. Le seul texte qui traite de réformes

35. Paul Doncœur, « la Jeunesse chrétienne dans la crise mondiale », p. 8.

36. Jacques Maritain, "Nature de la politique ", la Relève, vol. 2, no 5, p. 132. 
concrètes est un commentaire de Roger Duhamel sur le programme de la Distributist League anglaise. Duhamel y rappelle les principaux points de ce programme : restriction de la concurrence, lutte contre les cartels, lutte à la corruption électorale, participation de la classe ouvrière à la gestion et aux bénéfices des entreprises, nationalisation de certaines entreprises d'utilité publique, retour à la terre, etc., en souligne l'intérêt, émet des réserves sur la participation des travailleurs à la co-gestion des entreprises, condamne l'idée de la nationalisation car « l'étatisme ne résout rien, tout au plus retarde-t-il l'échéance en la grevant lourdement ${ }^{37}$ », et termine son article ainsi : «Par l'organisation professionnelle, par les corporations réadaptées à notre âge, par la propriété de plus en plus accessible, par le désir profond de la justice et de la charité, nous parviendrons à une civilisation plus humaine ${ }^{38}$. $\gg$ Duhamel fournit bien une solution : le corporatisme, mais cette solution est globale et il ne précise pas comment le corporatisme pourrait, pratiquement, remédier à la Crise.

Autre fait révélateur de cette attitude abstraite : la revue ne commentera pas les lois qui étaient alors proposées par les gouvernements pour remédier au chômage et à la misère. Ainsi passera-t-elle sous silence le programme proposé par Bennett en 1935 et qui prévoyait l'application de toute une série de mesures drastiques pour redresser la situation économique, la loi Taschereau sur la colonisation passée en 1935, les autres lois sociales votées en ces années-là (pensions de vieillesse, allocations aux mères nécessiteuses, salaire minimum, etc.). Dans la mesure où la Crise était définie comme un problème spirituel, un problème de civilisation, il n'est pas étonnant que la Relève n'ait pas réussi à proposer des solutions concrètes pour y remédier ; bien plus, il était presque fatal qu'il en soit ainsi. Car la solution de la Crise, pour la Relève, exigeait un renversement du système et l'établissement d'un ordre social chrétien, et ne pouvait donc être obtenue à coup de réformes partielles. Elle supposait une révolution, une transformation profonde et radicale de la société.

\section{B. La révolution}

Le monde actuel est pourri. Il n'y a plus rien à en attendre. Une transformation révolutionnaire de la société est nécessaire. Il y a urgence de créer un ordre nouveau. Ce genre de phrase revient souvent sous la plume des rédacteurs de la Relève. Mais qu'est-ce que la révolution pour eux ?

37. Roger Duhamel, "Une initiative anglaise ", la Relève, vol. 2, no 1, p. 27.

38. Ibid. 
C'est d'abord une «chance à tenter ». «L'avantage de la révolution, écrit Robert Charbonneau, c'est qu'elle propose un dogme positif, alors que l'ordre établi est tellement pourri qu'il n'a plus qu'une morale à nous offrir, une morale à principe de ne pas ${ }^{39}$. La révolution, dans un monde de désolation, représente un espoir.

Le régime actuel, c'est-à-dire le capitalisme libéral, est condamné parfois avec la dernière énergie. Nous disons parfois car la position de la revue à ce propos n'est pas toujours aussi ferme. À certains moments, on ne critique le capitalisme que pour ses abus alors qu'à d'autres on prétend qu'il est essentiellement vicié. Le texte suivant témoigne de l'énergie avec laquelle, parfois, il était condamné :

Le système industriel et capitaliste trouve son origine dans l'individualisme, l'atomisation de la société, la concupiscence déréglée du monde, le surpeuplement indéfini, la pléthore illimitée des besoins, la déchéance de la foi, l'affaiblissement de la vie spirituelle. Le capitalisme viole la véritable hiérarchie de la société et, à l'égal du socialisme, il accompagne la chute et l'extinction des créations spirituelles. Dans l'histoire moderne, le centre de gravité de l'existence passe de la sphère spirituelle à la sphère matérielle : la Bourse remplace l'Eglise comme force de vie ${ }^{40}$.

A remarquer, en passant, l'explication que proposent les rédacteurs de l'origine du capitalisme. Sa naissance n'est rattachée en rien ni à l'histoire des techniques de travail, ni de façon plus générale à l'évolution sociale et économique de l'humanité ; elle est présentée comme le fruit du surgissement de l'individualisme. Cet individualisme lui-même, les rédacteurs ne se demandent pas d'où il sourd, ils se contentent de le prendre comme une donnée sur laquelle ils fondent leur explication. À remarquer aussi que le capitalisme est condamné non pas tant en lui-même qu'en ce qu'il propose un modèle de société différent du modèle tenu pour le meilleur, soit celui de la société féodale, dans laquelle l'Église était «force de vie ».

Mounier, dans un texte publié dans un cahier du deuxième volume de la revue, condamnera, pour sa part, l'économie capitaliste qu'il juge profondément immorale parce que fondée «sur le mécanisme de la fécondité de l'argent, avec toutes les formes d'usure qui en découlent ». Explicitant sa pensée, Mounier écrira :

Nous lui reprochons surtout de subvertir complètement l'ordre de la vie humaine, en soumettant les exigences de la personne à celles de la pro-

39. Robert Charbonneau, "Jeunesse et révolution ", la Relève, vol. 2, no 1, p. 4.

40. "Un nouveau Moyen Age », la Relève, vol. 1, no 8, p. 213. 
duction, la production au profit d'argent et par suite au jeu artificiel et inhumain de la spéculation financière, de la vie politique, de l'opinion, des mœurs. Nous poursuivons enfin le mal jusqu'au cœur: le monde de l'argent a créé une zone chaque jour croissante d'humanité où les conditions matérielles minima nécessaires à une vie personnelle ne sont point remplies; là même où il desserre son étau, il a répandu cet esprit bourgeois qui est la négation de toutes les mystiques antérieures, la chrétienne comme la populaire, l'aristocrate comme la révolutionnaire ${ }^{\mathbf{* 1}}$.

Pour Mounier, le capitalisme était à détruire parce qu'il maintenait dans une condition sous-humaine la couche la plus nombreuse de la société, la classe prolétarienne. Et si pour Mounier, la révolution ne s'arrêtait pas avec la destruction de l'ordre capitaliste, elle n'en commençait pas moins là. La révolution intérieure, chez lui, était subordonnée à la révolution prolétarienne, du moins dans l'ordre de l'action. Dans l'ordre des valeurs bien sûr, la révolution intérieure primait l'autre. Mais pour qu'elle soit possible, il fallait d'abord abolir la domination des capitalistes sur la société.

Il était bien entendu que la révolution qu'on se proposait de faire serait différente de la révolution marxiste. «Il ne saurait pour nous, écrit Robert Élie, y avoir de choix entre communisme et monde bourgeois. Le premier n'est que l'achèvement du second, plus absolu, moins hypocrite parce que plus net ${ }^{42}$. 》 Dans un autre texte, on précisera en s'inspirant de Berdiaev :

L'humanisme a effectué le passage de l'homme de la «concrétion spirituelle $\gg$ où tout est organiquement lié, à l'abstraction divisante, où l'homme se trouve en un atome isolé. Cette tendance à l'abstraction aboutit aux deux formes extrêmes de l'atomisation : individualisme et socialisme. Nietzsche remplace le Dieu perdu par le surhomme, Marx, par la collectivité ; leur morale, à tous deux, nie la personnalité. En eux se consomme la fin de la Renaissance ${ }^{43}$.

Autrement dit, le capitalisme et le socialisme sont la conclusion naturelle d'un même phénomène, l'atomisation de l'homme, qui n'a cessé de gagner du terrain depuis la Renaissance. Le capitalisme et le socialisme sont les deux visages d'un même monstre : le matérialisme.

Ainsi donc, ces deux phénomènes, en dernière analyse, n'en constituent qu'un seul. Leurs différences s'effacent devant leurs ressemblances. Dans les deux

41. Emmanuel Mounier, e le Mouvement * Esprit ^, la Relève, vol. 2, no 8, p. 228-229. 42. Robert Elie, "Communion ", la Relève, vol. 2, n० 2, p. 46.

43. Un nouveau Moyen Age», la Releve, p. 211. 
systèmes, la personne est diminuée : dans le capitalisme, elle est abandonnée à elle-même et condamnée à la solitude; dans le socialisme, elle est absorbée dans le grand tout que forme la collectivité. C'est pourquoi ces deux systèmes doivent être remplacés par un autre qui redonne la primauté à la personne, cette primauté qui était la caractéristique essentielle de la synthèse chrétienne du Moyen Âge.

Comme on l'aura remarqué, la pensée des rédacteurs de la revue à ce propos s'inspirait très largement des réflexions de Maritain, Mounier, Berdiaev. Ouvrons donc ici une parenthèse pour rappeler que ces penseurs eurent une très large influence sur les collaborateurs de la Relève. Ajoutons encore le nom de Péguy à qui Paul Beaulieu consacrera un long article qu'il terminera par l'éloge suivant : "Au milieu du vieillissement du monde moderne, alors que toutes les fausses valeurs s'écroulent, on comprend que la nouvelle génération se retourne audacieusement vers cet homme et puise dans ses œuvres le rajeunissement, la vigueur nécessaire à tout renouveau ${ }^{44}$. $\gg$ Les rédacteurs de la revue d'ailleurs reconnaîtront aisément l'influence que ces hommes exercèrent sur eux et avoueront qu'ils furent leurs maîtres à penser. Maritain et Mounier surtout exercèrent une très grande influence sur la Relève qui publiera plusieurs articles écrits par eux et qui recourra souvent à leur autorité pour justifier ses prises de position. Et à parcourir quelques livres de Maritain, comme l'Humanisme intégral, et quelques livraisons d'Esprit, on peut, sans être méchant et sans exagérer, affirmer que les rédacteurs de la Relève prirent là l'essentiel de leur pensée. D'autres, on le sait, à la même époque, la prendront chez Barrès et Maurras. Ce qui n'est pas nécessairement un progrès, bien au contraire. Mais refermons cette parenthèse qui pourrait nous retenir longtemps car les rapprochements possibles entre la pensée des collaborateurs de la Relève et celle de Maritain et de Mounier pourraient constituer, à eux seuls, l'objet d'une thèse.

La Relève, tout en refusant la solution communiste, ne donnera pas dans la chasse aux sorcières. Elle sera plutôt portée à adopter le point de vue de Maritain et de Berdiaev pour qui le communisme était la preuve de l'échec historique du christianisme en tant que solution temporelle aux problèmes de l'humanité. Ce dernier écrira dans les Sources et le sens du communisme russe :

La révolution a éclaté dans l'histoire chrétienne comme un jugement porté sur le christianisme historique, sur les chrétiens, sur leur reniement des premiers préceptes, sur la caricature qu'ils ont faite du christianisme. C'est précisément pour les chrétiens que la révolution a un sens, ce sont eux 44. Paul Beaulieu, "Charles Péguy ', la Relève, vol. 1, no 5, p. 164. 
qui doivent avant tout la comprendre, elle est pour eux un appel, une évocation de cette justice qu'ils n'ont pas su réaliser ${ }^{45}$.

En d'autres termes, avant d'accuser les communistes, les chrétiens doivent d'abord faire leur propre procès. Car la révolution est la conséquence de leur échec. Pour Berdiaev, d'une certaine façon, les chrétiens sont les véritables responsables de la révolution, à défaut d'être ses auteurs. C'était à eux de faire la révolution ; or, ils ne l'ont pas faite. Les communistes ont comblé le vide. Il leur appartient maintenant de faire en sorte qu'il n'en soit plus ainsi en réalisant la révolution personnaliste.

L'ordre nouveau qu'il s'agit d'instaurer doit être fondé sur la restauration de la personne. La société doit être réaménagée en fonction de celle-ci. Reprenant le mot d'ordre de Péguy, "la révolution sera morale ou ne sera pas », les rédacteurs de la Relève entendaient signifier que la révolution consistait d'abord et avant tout à changer l'homme, si bien que «le perfectionnement matériel, pouvait écrire Paul Beaulieu, n'a pas sa raison d'être s'il empêche la liberté intérieure ${ }^{46}$ \$. C'est qu'il s'agit de créer un homme nouveau. Entreprise difficile entre toutes, qui sera longue et semée d'écueils mais qui vaut d'être menée à terme. Robert Élie, dans un texte au langage obscur, comme c'est généralement le cas lorsqu'il s'agit de lui, écrit qu'il faudra «rééduquer»l'homme «quitte à se refuser les trompeuses conquêtes de ceux qui aveuglent et énervent pour entraîner, quitte à ne travailler que par progression lente ${ }^{47} \gg$.

Ceci dit, par qui et comment sera faite la révolution ? Et quel visage prendra au juste cette révolution? Quelle société en somme s'agit-il de construire?

Par qui sera-t-elle faite ? Par chacun de nous, répond Hurtubise dans un article consacré à la révolution spirituelle, car «chacun de nous participe au scandale actuel et en est responsable à quelque degré ${ }^{48}$ ». Et Daniel-Rops, pour sa part, précisera :

Cependant il serait vain d'attendre que ce monde se réalisât tout seul. L'humanité ne sera transformée que si les hommes se réforment un à un, par un effort personnel de rénovation. L'Evangile qui contient les lois de

45. Nicolas Berdiaev, les Sources et le sens du communisme russe, Paris, Gallimard, - Idées », 1963, 373 pages. Ecrit en 1935, publié en 1938.

46. Paul Beaulieu, "Charles Péguy 》, p. 158.

47. Robert Elie, « Espérance pour les vivants », la Relève, vol. 3, no 3, p. 80. no 3, p. 78

48. Claude Hurtubise, "De la révolution spirituelle, préliminaire », la Relève, vol. 2, 
ce renouvellement reste donc le message inégalé et seul capable d'opérer le relèvement de notre société ${ }^{49}$.

Par ailleurs, la Relève ne croit pas à l'action politique dans le cadre des partis traditionnels qu'elle juge pourris jusqu'à la moelle et ne croit guère à l'action politique en général. Elle est donc extrêmement discrète sur le comment de la révolution - elle parlera bien parfois d'une action sur l'élite, mais ne donnera pas plus de précisions; elle ne dispose, pour la réaliser, ni de stratégie ni de tactique. Il est vrai que ne la situant pas d'abord sur le terrain économique et politique, il ne pouvait guère en être autrement.

Son attitude ne plaira pas à tout le monde. Jean-Louis Gagnon, entre autres, qui était à l'époque un «farouche » révolutionnaire, s'en prendra vigoureusement à Robert Charbonneau dans une Lettre à celui-ci publiée dans la revue les Idées en janvier 1936. Le propagandiste de la révolution nationale socialiste québécoise attaquait la position de Charbonneau à partir d'un paragraphe que ce dernier avait écrit sur un article de Jean-Charles Harvey. Ce paragraphe était le suivant : "Il [Jean-Charles Harvey] oublie que ce sont de ces aînés que nous nous recommandons et que le capitalisme pour un Daniel-Rops, un Maritain, un Mounier importe moins que le retour aux valeurs spirituelles de charité et de bonté. »

Considérant que Charbonneau traitait le problème de la révolution dans l'absolu, Gagnon se proposait de situer la discussion dans le fini. Pour lui, Charbonneau avait le tort de ne pas situer la révolution sur le plan politique. Il ne suffit pas de condamner le capitalisme du bout des lèvres disait en somme Gagnon, il faut la détruire dans ceux qui l'incarnent :

Supposons, écrivait-il, que le capitalisme appliqué par les grands Chinois de St-James Street soit cause de tous les bobos dont nous souffrons. Eh bien! je vous parie votre part de paradis contre la mienne, que vous n'obtiendrez ni la disparition des Chinois ni de leurs chinoiseries financières par votre retour aux valeurs spirituelles de charité et de bonté. Par contre, ce retour est rendu possible par la disparition des Chinois et de leurs chinoiseries ${ }^{50}$.

Précisant sa pensée, Gagnon poursuivait en écrivant que la révolution avant d'être un problème de rénovation spirituelle était une affaire de tripes:

49. Daniel-Rops, « Lettre de France », la Relève, vol. 4, no 4, p. 110-111.

50. Jean-Louis Gagnon, «ettre à Charbonneau », les Idées, janvier 1936, p. 43-54. 
Mon cher Charbonneau, la Faim, c'est la fin du monde.

Le ventre d'abord!

Le Pain, c'est la première des vertus, c'est le produit chimique qui résume le monde.

Le Pain, c'est la formule un qui se pose en antithèse à la formule zéro la Faim.

Au mort d'ordre : spirituel d'abord, Gagnon opposait celui de : «le ventre d'abord!»Et commentant la phrase citée plus haut, qui lui avait servi de prétexte pour s'attaquer à Charbonneau, il écrivait : «Un retour à la bonté et à la charité est une impossibilité physique. Comme disait Monseigneur Lebond : c'est difficile d'être vertueux quand on est pauvre. »Il terminait sa lettre en rappelant que « notre lutte est et reste une lutte politique d'abord ».

Charbonneau répondra à Gagnon de la façon suivante ${ }^{51}: 1$. La misère est en nous. St-James Street en est une forme, mais la suppression des Chinois de cette rue ne détruirait pas la misère, elle ne détruirait que des Chinois. > Autrement dit, la misère est morale avant que d'être matérielle. La misère matérielle ne «représente qu'un aspect terrible, mais en somme accidentel de la crise de civilisation que nous traversons. Elle ne doit pas nous aveugler sur le problème réel qui est beaucoup plus vaste ». 2. "Cela ne veut pas dire que nous devons oublier les ventres-creux, mais bien que nous ne devons pas sous prétexte d'entraide nous perdre avec eux. $\gg 3$. La charité, vertu chrétienne par excellence, doit nous guider dans le soulagement de la misère. Et d'ailleurs, « la charité, bien comprise et vécue, est bien plus forte qu'une révolution dans laquelle rien d'essentiel n'est engagé ». 4. Le renversement de «St-James Street 》ne réglerait en rien le problème en profondeur, aussi ce que nous devons d'abord désirer c'est, d'une part, le « rétablissement de ces grandes vertus et de la justice » et, d'autre part, la transformation de l'homme car il est nécessaire de «changer l'homme avant de renverser St-James Street ».

Gagnon, dans une seconde lettre ${ }^{52}$ publiée dans les Idées en septembre 1936 poursuivra la polémique. Il répondra à Charbonneau que la misère n'est pas en nous, mais sur nous, autrement dit qu'elle ne provient pas d'une déficience de l'homme mais du fait que le contrôle de la société est assuré par des hommes, p. $163-165$.

51. Robert Charbonneau, « Réponse à Jean-Louis Gagnon *, la Relève, vol. 2, no 6,

52. Jean-Louis Gagnon, - Deuxième lettre à Robert Charbonneau », les Idées, septembre 1936, p. 159-168. 
les financiers de «St-James Street », qui ont intérêt à ce que les gens demeurent dans la misère. Il ajoutera : nous sommes solidaires des ventres-creux et nous devons les appuyer dans leur combat. Enfin, reprenant l'argumentation qu'il avait développée dans sa première lettre, il écrira que «ce n'est pas en changeant l'homme qu'on renversera St-James Street mais bel et bien en renversant St-James Street qu'on finira par changer tout ça ». Pour Gagnon, il est donc évident que toute transformation sérieuse de la condition de l'homme implique et exige le renversement préalable du système en place. On sait qu’à cette époque Gagnon voulait substituer à ce système l'économie corporative fasciste, grand admirateur de Mussolini qu'il était.

Charbonneau ne répondra pas à cette nouvelle lettre de Gagnon. Le débat sera cependant relancé à nouveau par la publication dans la Relève d'une lettre de Pierre Mackay Dansereau à Robert Charbonneau ${ }^{53}$. Relancé, c'est une façon de parler, car Charbonneau refusera de répondre à Dansereau. Pour toute réponse, on se contentera de publier la note suivante en marge de la lettre de Dansereau :

Cette lettre que nous publions parce qu'elle exprime un état d'esprit très répandu, nous en laissons l'entière responsabilité à son auteur. Nos positions sont radicalement opposées. Tout ce qui a été publié ici l'atteste et la «réponse à Jean-Louis Gagnon» publiée dans le 6ème cahier de la 2ème série réfutait par avance ces idées ${ }^{54}$.

Dansereau reprenait en substance les idées auparavant développées par Jean-Louis Gagnon. Ne niant pas l'importance de la révolution intérieure, "pour que le révolutionnaire soit fort et son action efficace et durable », Dansereau ajoutait cependant immédiatement que «la révolution digne de ce nom ne peut se maintenir uniquement sur le plan spirituel» et que «l'action, c'est la politique ou bien, c'est du cabotinage ». Et il terminait sa lettre par la constatation suivante : "Une chose entre toutes me paraît triste : l'horreur de la réalité suivie de la fuite dans la forêt des symboles et des abstractions. »

Il est malheureux en un sens que Charbonneau ait préféré clore la discussion. Car finalement chacun resta sur ses positions et la question demeura aussi embrouillée. Qui avait tort, qui avait raison? On peut aujourd'hui, avec le recul du temps, juger que Gagnon et Dansereau avaient fondamentalement raison. En

53. Pierre Mackay Dansereau, «Lettre à Robert Charbonneau », la Relève, vol. 3, no 2 , p. $58-62$.

54. Note de la rédaction », la Relève, vol. 3 , no 2, p. 58. 
refusant de donner à sa révolution un contenu politique, Charbonneau se vouait à la stérilité. En fait, la révolution qu'il désirait exigeait à la fois un changement de l'individu et une transformation de la société, ces deux changements se déroulant simultanément et se renforçant l'un l'autre. En refusant d'agir sur le plan politique, les collaborateurs de la revue se vouaient à l'échec. D'un autre côté, on peut dire qu'aucun des trois correspondants n'aborda les vrais problèmes, car à supposer même qu'ils se soient entendus pour accorder la priorité à la révolution politique, il leur aurait encore fallu se demander par qui et au nom de qui cette révolution devait être faite. Pour répondre à cette question, il leur aurait fallu analyser la société québécoise, voir quels groupes à l'intérieur de cette société désiraient un changement révolutionnaire, élaborer à partir de cette analyse une stratégie de l'action, bâtir un programme, etc. Or, dans aucune des lettres, ces problèmes ne sont envisagés. Jamais on ne se demande si une révolution au Québec est seulement possible. Toujours la polémique se situe sur le plan théorique, abstrait, conserve l'allure d'une discussion d'école. Si nous avons consacré autant d'espace à cette polémique, c'est qu'elle nous paraît d'une très grande importance pour la compréhension de l'échec du projet des rédacteurs de la Relève de créer un ordre et un homme nouveaux. Nous reviendrons là-dessus dans notre conclusion générale.

Nous l'avons vu plus haut: à la suite notamment de Mounier, les rédacteurs de la Relève avaient rejeté à la fois le capitalisme libéral et le communisme comme bases d'un ordre temporel nouveau. Ils seront toutefois plus lents à condamner définitivement le fascisme qui, dans les premiers temps de la revue, leur apparaîtra sous un jour séduisant en tant que tentative d'incarnation d'un régime corporatif. Refusant ces trois formes de régime politique, sans abandonner leurs idées corporatistes cependant, comme nous le verrons tantôt, ils déposeront leur espoir dans une société qui serait à la fois personnaliste et communautaire. Un tel type de société leur paraîtra désirable parce que fondé sur la double affirmation, d'une part, que l'homme est un être social, dont la société est le cadre naturel d'épanouissement, d'autre part, que l'homme, être spirituel et libre, n'est pas qu'un rouage d'un système social et qu'il doit se réaliser de façon autonome et personnelle. Pour Pierre-Henri Simon :

Le personnalisme correspond ainsi à un mouvement dialectique, d'une part pour rattacher normalement l'individu, en tant qu'être historique, à une solidarité économique, sociale et politique hors de laquelle il ne saurait vivre, et d'autre part pour sauvegarder en chacun ce qui le fait homme, 
l'orientation de sa pensée sur des valeurs morales transcendantes et, pour la servir, une liberté spirituelle protégée contre la pression des lois 5.

Si, au niveau des principes, la Relève faisait sien le personnalisme d'Esprit, il reste qu'elle ne développa guère ce thème. Ainsi ses réflexions sur le corporatisme, qui furent assez nombreuses, rattachèrent rarement cette dernière préoccupation, d'ordre pratique, à la préoccupation, plus théorique par rapport à la première, d'un ordre personnaliste et communautaire à créer. Peut-être ce lien lui paraissait-il trop évident pour faire l'objet d'une démonstration? Quoi qu'il en soit, nous aurons pour notre part à le faire.

Dès le quatrième numéro du premier volume de la Relève, Roger Duhamel notera avec satisfaction le rôle joué par Dollfuss en Autriche et Salazar au Portugal et se réjouira de ce que dans «tous les pays, des mouvements de base doctrinale rallient des milliers d'adhérents, pour mener à bonne fin le combat de la personnalité, pour l'intégrer organiquement dans un ordre transcendant, au lieu de l'abandonner à l'atomisation du libéralisme démocratique ou du marxisme de toutes nuances ${ }^{56} \gg$. Poursuivant sa pensée, Duhamel écrira :

Pour réaliser cette conception de la société, il faut une doctrine à la fois religieuse, sociale, économique et politique. Cette charte, nous la trouvons, au moins quant à ses lignes essentielles, dans les institutions corporatives du Moyen Age ${ }^{57}$.

Duhamel, dans les numéros de la revue qui suivront, écrira une longue étude historique sur le régime corporatif, depuis les premières corporations du Moyen Âge jusqu'au régime corporatiste fasciste italien. Après avoir longuement décrit la corporation médiévale, fondée sur la hiérarchie : apprenti, ouvrier, maître, montré que ce régime assurait l'excellence du métier et aplanissait en quelque sorte, à l'avance, en raison de sa structure même, les conflits sociaux, il terminait son étude en écrivant que le fascisme italien avait mis fin à l' "irréductible antagonisme qui oppose les classes dans une lutte stérile», qu'il avait ordonné la concurrence, «sauvé de la débâcle la propriété privée, fondée en droit naturel » et «provoqué la renaissance de l'esprit public, en atténuant les conflits sociaux par la suppression réelle des grèves et des lock-out ${ }^{58} \gg$. Précisons toutefois que

55. Pierre-Henri Simon, Histoire de notre temps, no 5, printemps 1969, p. 29 ; rapporté dans Jean-Louis Loubet Del Bayle, op. cit., p. 344.

56. Roger Duhamel, "Pour un ordre nouveau ", la Relève, vol. 1, no 4, p. 83.

57. Ibid., p. 84.

58. Roger Duhamel, "l'Ordre corporatif sous le signe du fiasco •, la Relève, vol. 1, no 8, p. 198 et 202. 
Duhamel n'accordait pas sa bénédiction au fascisme les yeux fermés : il dénonçait, en la regrettant, la fâcheuse tendance autoritariste de celui-ci.

La solution corporatiste perdit peu à peu son attrait pour les collaborateurs de la Relève, si bien que dans les dernières années de la revue, on n'en parla presque plus. Jugea-t-on qu'elle ne convenait pas au Québec? Rien ne nous permet d'affirmer que ses rédacteurs le pensèrent. Rien ne nous permet non plus d'affirmer le contraire. Ici, toutes les spéculations sont permises.

Avant de passer à la section suivante, résumons en quelques lignes l'essentiel des idées développées dans celle-ci. Le monde actuel, pour les rédacteurs de la Relève, doit être rejeté. Pourquoi ? Parce qu'il ne respecte pas la véritable hiérarchie des valeurs. Or cette hiérarchie, comme nous l'avons déjà expliqué, est fondée sur la primauté des valeurs spirituelles. Or le monde actuel place au rang le plus élevé les valeurs matérielles, ne se préoccupe du déveoppement de l'homme qu'en tant qu'individu et non en tant que personne. Il faut donc créer un ordre nouveau qui redonne la primauté aux valeurs spirituelles et à la personne. À ce titre, la solution personnaliste et communautaire proposée par Esprit présente beaucoup d'intérêt. Elle a le mérite de réintégrer l'homme dans la communauté sans dissoudre sa personnalité. Elle permet d'échapper au double piège de l'individualisme et du totalitarisme. Le corporatisme, par ailleurs, semble pouvoir répondre au désir formulé par les collaborateurs de la revue d'un monde stable, ordonné, sans conflit, uni organiquement. Par le corporatisme, l'homme évitera des luttes inutiles et sera par ailleurs fortement intégré dans une communauté vivante qui lui permettra de s'épanouir tout en lui épargnant l'angoisse que sa solitude dans le monde actuel a développée en lui. Cependant, il n'est pas question d'établir cet ordre nouveau par une révolution politique. Que l'homme commence d'abord par se transformer lui-même, la société en sera améliorée d'autant. La révolution doit être morale et spirituelle avant que d'être politique et économique. Paul Beaulieu, dans un article sur le Père Doncœur, écrira que ce dernier sait qu'il n'y a qu'un remède à la Crise : « réapprendre au monde le Christ, que pour réapprendre, il faut s'inspirer des époques chrétiennes, puiser aux sources primi-

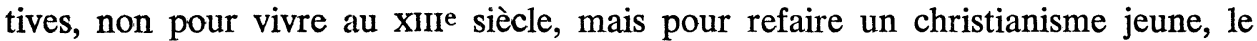
seul vrai d'ailleurs, qui réponde à nos besoins ${ }^{59}$ ». On le voit : les projets de réforme sociale et politique des collaborateurs de la Relève sont une incarnation de leur vision du monde et, pour autant, souffrent des lacunes de celle-ci. Une vol. $1, \mathrm{n}^{\circ} 1$, p. 6.

59. Paul Beaulieu, "Prédicateur de jeunesse : le Père Paul Doncœur", la Relève, 
vision du monde comme celle qui était la leur ne pouvait guère donner lieu qu’à des réformes abstraites et par conséquent sans prises sur le réel. Remarquons, enfin, que le système établi, qu'on condamne énergiquement, n'est jamais ou trop rarement étudié en tant que tel, et lorsqu'il l'est, il est jugé non pas à partir d'une analyse sociale et économique par exemple, mais à partir de principes abstraits. Et surtout, il est jugé par comparaison avec un système idéal qu'on estime lui être supérieur, système lui-même établi sur une conception abstraite des valeurs.

\section{Le catholicisme}

Ainsi que nous l'avons vu dans la première partie de ce travail, la Relève, dès le premier texte du tout premier numéro, avait manifesté son intention de poursuivre ses recherches à la lumière du catholicisme : "Le catholicisme, y disait-on notamment, est un terrain de rencontre. En lui seul peut s'élaborer une doctrine tenant compte des diverses tendances modernes, respectant les particularismes de race, mettant également en valeur la personne humaine et la plénitude de la vérité ${ }^{60}$. $\gg$ La revue allait effectivement tenir parole comme on a pu s'en rendre compte à la lecture de ce qui précède. Cependant, toutes proportions gardées, elle consacra moins d'espace à la question religieuse proprement dite qu'aux questions comme la Crise, la révolution à faire, etc. Et comme sa réflexion s'orienta dans plusieurs directions, il nous faudra, pour en rendre compte, passer parfois assez abruptement d'un sujet à un autre. On nous pardonnera donc le décousu de notre exposé sur ce point.

À aucun moment, dans toute l'existence de la revue, on ne trouve de véritable analyse du catholicisme canadien-français. Bien sûr, le catholicisme des nôtres, à un homme comme Berthelot Brunet, par exemple, paraîtra bien fade et il n'hésitera pas à le dire avec la verve qu'on lui connaît :

Bien entendu, comme la plupart des Français, nous sommes presque tous des baptisés, et la majorité des Laurentiens va à la messe. Il y a même pas mal de processions, d'innombrables ligues et confréries, des dévots remuants, des politiques de sacristie, des inquisiteurs et des mouchards en veux-tu en voilà, mais de catholiques vrais, je crois qu'on peut les compter. Nos curés ont beau écrire : je me demande si l'on pourrait tirer vingt-cinq pages d'une piété authentique de ce puits sans fond ${ }^{61}$.

60. La Releve, Positions », vol. 1, no 1, p. 2.

61. Berthelot Brunet, «Primaires et doctrinaires ou l'Ecole des dupes *, la Nouvelle Relève, vol. 3 , no 4 , p. 220. 
Mais, ceci dit, Berthelot Brunet lui-même faisant preuve de la même superficialité que les catholiques mous qu'il dénonce, n'essaie pas de pousser plus loin son analyse, ne propose pas d'explication du phénomène qu'il se borne à enregistrer. Il y avait pourtant là un problème essentiel : comment se fait-il que dans un pays officiellement catholique comme le Québec, la foi vive, la vraie foi, soit si faible ? À cette question, Brunet ne répond pas plus que LeMoyne, notre théologien laïc qui, dans un texte très dur ${ }^{62}$, pourfendra avec la dernière énergie la façon dont les chrétiens d'ici assistent aux offices religieux, à la messe en particulier, témoignant ainsi de leur peu d'engagement en profondeur dans la foi. Dans un cas comme dans l'autre, le conformisme religieux des chrétiens d'ici est dénoncé mais non expliqué.

Avant eux, le Père Doncour, célèbre prêcheur français venu ici dans l'espoir de rallier notre jeunesse afin de l'engager dans le grand combat qui, selon lui, se préparait entre les forces païennes et les forces chrétiennes, avait fait une constatation analogue ${ }^{63}$. Notre jeunesse, avait-il remarqué, quoique pouvant apporter un "renfort magnifique » à la jeune croisade chrétienne qu'il voulait mettre en branle, n'était pas prête pour le combat. Ni intellectuellement, parce que n'ayant pas eu à défendre sa foi, n'ayant pas connu l'angoisse du doute, ni les persécutions doctrinales, notre jeunesse s'était installée dans un catholicisme de routine, ni moralement, en raison du fait que le catholicisme ici étant acquis à la naissance et officiellement reconnu par tous, notre jeunesse n'a pas eu à le défendre et à tremper sa foi dans le combat. Or le combat qui s'annonce exigera un catholicisme de combat et seuls les catholiques qui sauront faire preuve d'héroïsme pourront le mener à bien. Aussi le Père Doncœur exhortait-il notre jeunesse à renoncer au confort bourgeois et à se fortifier moralement par une discipline sévère. Certains collaborateurs de la Relève, prenant au sérieux les remarques du Père Doncœur, participeront aux pèlerinages que celui-ci organisait en Terre sainte, qui étaient, pour eux, une façon de renouer avec la grande tradition de l'héroïsme chrétien, avec celle glorieuse des croisades. Paul Beaulieu, qui a fait le pèlerinage, exprime ainsi son enthousiasme :

Tenter de revivre plus étroitement les années que le Christ a passées sur la terre, marcher sur ses traces, mettre nos pas dans ses pas, parcourir durement, sac au dos, sous un soleil brûlant, les routes plates, gravir péniblement les montagnes ternes, dormir sur le sol rocailleux qui blesse le

62. Jean LeMoyne, la Messe ici », la Nouvelle Relève, vol. 2, no 5, p. 306-310. vol. $1, \mathrm{n}^{\circ} 2$.

63. Paul Doncœur, a Jeunese chrétienne dans la Crise mondiale ", la Relève, 
corps mais fortifie l'âme, être regardé par les étoiles qui ont vu le Maître, n'y a-t-il pas de quoi enthousiasmer les moins jeunes? Renouer cette tradition des pèlerins moyen-âgeux, comme eux vider son sac à péchés et aussi celui de nos frères. Accomplir tout ce pèlerinage dans la joie, dans le calme, dans la pauvreté ${ }^{64}$.

Le pèlerinage était une façon de rompre avec le conformisme religieux ambiant, une façon de vivre son christianisme de façon authentique, en l'éprouvant en quelque sorte dans sa chair. Sur la façon de pratiquer le culte religieux, sur la manière dont celui-ci est pratiqué chez nous, la réflexion des rédacteurs de la Relève, comme on peut le constater, n'est guère abondante.

Dieu agit sur le monde par sa Providence. On reviendra à quelques reprises sur ce thème. Ainsi, Roger Duhamel, passant en revue le travail accompli par les mouvements de jeunesse durant l'année 1935, commentera en ces termes l'action des Jeune-Canada : «À eux nous sommes comptables d'avoir compris qu'une nationalité - tout comme un individu - ne vit pas seulement de pain, mais de toute parole qui situe sa mission dans le plan déterminé par la Providence ${ }^{65}$. $\gg$ C'est donc la Providence qui tire les ficelles du monde et l'homme et la nation sont ses instruments : ils doivent collaborer à la réalisation de son plan d'ensemble. Ceci dit, comment savoir si l'on agit bien dans le sens voulu par la Providence? Comment, en d'autres termes, celle-ci se manifeste-t-elle, fait-elle connaître sa volonté ? Duhamel ne se pose pas la question, de crainte, on peut le supposer, de ne pas trouver de réponse. Un collaborateur de circonstance de la revue, J.-Conrad Lemieux, lui, est moins timide. Connaissant, lui, la volonté de la Providence, l'ayant lue sans doute dans quelque boule de cristal, il préviendra ses jeunes compatriotes du grand dessein que celle-ci réserve au Canada français : «Jeunes Laurentiens, rêvez des plus grands espoirs. L’État français qui s'affirme, la Providence vous défend déjà de le limiter au berceau de la race. Il est beau d'envisager un territoire futur, mais il est encore plus grand d'en préparer les cœurs ${ }^{66}$. $\gg$ Il est d'autant plus convaincu de la mission du Canada français qu'un événement récent, la naissance des quintuplées Dionne dans les pays d'en-haut, constitue « une figure et un symbole» de la volonté divine. Dans cette naissance, il voit une manifestation de la Providence qui n'a pas oublié notre

p. 49.

64. Paul Beaulieu, "Camp avec le Christ, carnet de route ", la Relève, vol. 1, no 3,

65. Roger Duhamel, Voies de la jeunesse », la Relève, vol. 2, no 5, p. 153.

66. J.-Conrad Lemieux, "En marge des préliminaires à un manifeste pour la patrie *, la Relève, vol. 3, no 4, p. 119. 
peuple au milieu de ses misères et qui lui indique ainsi le sens de son destin. Précisons que J.-Conrad Lemieux n'était pas un collaborateur régulier de la Relève, que la pensée des rédacteurs de la revue ne peut donc être confondue sans réserves avec la sienne, mais que cette dernière, néanmoins, n'est pas incompatible avec la pensée des rédacteurs de la Relève : bien au contraire, elle illustre seulement les absurdités où celle-ci pouvait conduire. Mais n'insistons pas trop là-dessus car si, dans la doctrine de la Relève, l'existence de la Providence était postulée, dans la pratique on ne l'invoquait guère pour justifier des prises de position concrètes.

Le chrétien a un rôle temporel à jouer. Exerçant ce rôle, il ne change pas de nature : dans le domaine temporel comme dans le domaine spirituel, il demeure toujours chrétien. Agissant en tant que chrétien, selon la distinction célèbre de Maritain, il agit alors au nom de l'Église, dont il défend les solutions, et non en son nom propre. Agissant en chrétien, il travaille à l'instauration d'un régime social temporel où passe en quelque façon une réfraction terrestre des valeurs évangéliques ${ }^{67}$.

Ce régime social temporel qu'il s'agit d'instaurer, on le sait, s'inspirera fortement du régime temporel du Moyen Âge. Comme celui-ci, il sera communautaire, c'est-à-dire fondé sur la primauté du bien commun lui-même ordonné à la fin supra-temporelle de l'homme, personnaliste, c'est-à-dire organisé en fonction d'un développement maximum de la personne, pérégrinal, c'est-à-dire transitoire, subordonné à la mission essentielle d'assurer le salut de ses sujets. Mais il en différera sur quelques points ${ }^{68}$.

1. Alors que le régime temporel du Moyen Âge constituait une unité organique, qui n'admettait pas le pluralisme religieux, le nouveau régime admettra la diversité religieuse et favorisera la participation des chrétiens et des incroyants à l'œuvre commune.

2. Alors que le régime temporel du Moyen Âge avait pour fin première le service de Dieu et était conçu comme cause instrumentale de celui-ci, le nouveau régime sera fondé sur une certaine autonomie du spirituel, autonomie relative évidemment car il doit être organisé de telle façon que la vie contemplative des citoyens soit facilitée au maximum.

67. Jacques Maritain, « Nature de la politique s, la Relève, vol. 2, no 5, p. 132. vol. $1, \mathrm{n}^{\circ} 5$.

68. On trouvera ce point longuement développé dans un article signé La Relève, 
3. Alors que dans le régime temporel du Moyen Âge, l'hérétique était considéré comme un déviant qu'on faisait entrer de force dans le rang ou qu'on expulsait de la communauté (et parfois pour toujours, rappelons-nous l'Inquisition), le nouveau régime sera fondé sur le respect de la liberté de la personne.

4. Alors que dans le régime temporel du Moyen Âge, régnait une très grande disparité entre les dirigeants et les dirigés, le nouveau régime sera fondé sur la notion d'égalité d'essence entre dirigeants et dirigés. Le nouveau régime sera non pas autocratique comme l'ancien mais démocratique.

5. Enfin, alors que l'œuvre du régime temporel du Moyen Âge était d'abord définie comme œuvre divine, celle du nouveau régime sera d'abord définie comme œuvre humaine, que féconderont bien entendu les principes évangéliques.

Maritain, dans Humanisme intégral, définira en ces termes la tâche nouvelle du chrétien :

Le but que le chrétien se propose dans son activité temporelle n'est pas de faire de ce monde lui-même le royaume de Dieu, c'est de faire de ce monde, selon l'idéal historique appelé par les différents âges et si je puis dire par les mues de celui-ci, le lieu d'une vie terrestre véritablement et pleinement humaine, c'est-à-dire pleine de défaillances assurément, mais pleine aussi d'amour, dont les structures sociales aient pour mesure la justice, la dignité de la personne humaine, l'amour fraternel, et qui pour autant prépare l'avènement du royaume de Dieu d'une façon filiale, non servile, je veux dire par le bien qui fructifie en bien, non par le mal qui, tout en allant vers son lieu propre, sert au bien comme par violence ${ }^{69}$.

Et il ajoutera que c'est là faire œuvre de sainteté. C'est que le monde moderne appelle à de nouvelles formes de sainteté. Celle-ci n'est pas le privilège des seuls mystiques ou des prêtres. La vie profane a besoin d'être sanctifiée et il appartiendra aux laïques chrétiens de faire en sorte qu'elle le soit. En travaillant dans ce sens, ils feront un travail de saint.

Cette transformation du monde devra être faite à la lumière du christianisme, nous l'avons déjà souligné, et plus précisément à celle de la philosophie thomiste. Pourquoi ? Claude Hurtubise en donne la raison en ces termes :

Seule ia synthèse thomiste, parce qu'elle admet l'être dans sa totalité comme un fait inéluctable, a construit à l'image de la Création un organisme où

69. Jacques Maritain, Humanisme intégral, Paris, Fernand Aubier, 1936, 334 pages. 
les réalités supérieures sont affirmées, où la hiérarchie des valeurs est respectée, où chaque être trouvant sa place, le conflit entre les aspirations de chacun à la prééminence est résolu et l'ordre satisfait. Conception cosmique, comme chez Claudel, qui comprend l'être depuis le plus infime jusqu'à l'Etre suprême, commencement et fin de toutes choses ${ }^{70}$.

Autrement dit, le thomisme se présente comme une totalité analogue à celle qu'incarnait pour les rédacteurs de la Relève, le Moyen Âge chrétien. Sur le plan de la philosophie, il est l'expression du Moyen Âge traduit en idée : il est à la fois modèle et justification du système concret d'organisation sociale. C'est pourquoi, dans la construction de la chrétienté nouvelle, on devra s'en inspirer largement puisqu'il sera en quelque sorte la couronne intellectuelle de l'édifice qu'on se propose de construire.

Sur la question des rapports entre le catholicisme et le socialisme, la position de la Relève connaîtra une évolution sensible. Pie XI, en 1931, dans l'encyclique Quadragesimo Anno avait écrit que «personne ne peut être en même temps bon catholique et vrai socialiste ». Fidèle à la position papale, la Relève, au début, sera très réticente à l'égard du socialisme. Puis, avec les années, le socialisme se faisant moins virulent, abandonnant progressivement ses positions doctrinaires sur la propriété et la lutte des classes, ou du moins ne les invoquant plus que du bout des lèvres, et s'en inspirant peu dans l'élaboration de ses stratégies, les rédacteurs de la Relève finiront par admettre que la collaboration des socialistes et des catholiques est non seulement possible mais même nécessaire dans certains cas. Ainsi, serait-elle hautement souhaitable pour la construction de l'Europe après la guerre. C'est la conclusion que tirera un jésuite, le Père Dunne, dans la Nouvelle Relève : «Il est d'une importance primordiale tant pour l'intérêt de chacun que pour l'intérêt des peuples européens que des relations pacifiques se nouent entre le catholicisme et le socialisme. Il n'est d'espoir que l'Europe trouve un moyen terme entre deux extrêmes, la violence et la tyrannie, que dans un esprit de compréhension et de collaboration réciproque ${ }^{71}$. $\gg \mathrm{Ce}$ problème du dialogue des catholiques et des socialistes ne fut pas un thème important de la revue, comme ce fut le cas en France, par exemple, pour Esprit. Il est vrai qu'en France les catholiques, surtout ceux qui se vou-

70. Claude Hurtubise, "Saint Thomas d'Aquin de Chesterton », la Relève, vol. 2, no 1, p. 21.

71. Georges H. Dunne, "Socialisme et socialisme », la Nouvelle Relève, vol. 4, no 8 , p. 676. 
laient révolutionnaires, devaient fatalement se poser le problème de la collaboration avec les socialistes et les communistes et engager le dialogue avec eux. $\mathrm{Au}$ Québec, où les socialistes et les communistes n'existaient pratiquement pas, il est donc normal que la question n'ait pas fait l'objet de beaucoup d'attention.

Ce dernier développement, on l'aura remarqué, complète et précise les idées présentées dans les sections un et deux de cette partie. Nous avons choisi de le faire figurer ici pour bien montrer que l'organisation temporelle du monde nouveau qu'il s'agit de créer est le résultat direct d'une certaine conception chrétienne, la conception néothomiste, du monde et des choses. Conception qui est elle-même une variante de la vision du monde exposée dans la deuxième partie. Encore ici, nous pourrions reprendre la remarque sur laquelle nous avons terminé nos sections un et deux : la réflexion des rédacteurs de la Relève sur le catholicisme se maintint toujours à un haut degré d'abstraction, d'une part, et, d'autre part, lorsqu'elle se fit à l'occasion plus concrète, dégénéra en une critique superficielle du conformisme du catholicisme québécois. Jamais elle ne se livra à une analyse sérieuse de ce conformisme. Ce n'est que beaucoup plus tard que Jean LeMoyne, dans ses Convergences, se livrera à une telle analyse et montrera que le catholicisme québécois à souffert d'un double mal, le cléricalisme et le dualisme. Dans la revue elle-même, on ne trouve que des exhortations à vivre mieux son catholicisme.

\section{L'histoire}

L'histoire, pour les rédacteurs de la Relève, n'est pas une pure activité désintéressée. L'histoire éclaire le présent. Mieux, l'histoire aide à agir dans le présent. L'histoire est source de cohésion nationale. Un peuple sans histoire est un peuple déraciné. Tout grand peuple a une histoire et se reconnaît en elle. Mais lisons plutôt ce qu'écrit là-dessus Roger Duhamel :

L'histoire constitue, sans aucun doute, le meilleur réservoir des énergies nationales. C'est en se penchant sur le passé de notre pays, en considérant les hommes apporter leur effort au grand œuvre commun, que s'éveille en nous, dans les replis de la conscience, le sens instinctif de la solidarité ethnique. Nous nous sentons ainsi reliés, dans notre lutte quotidienne, à une chaîne nouée de tous les sacrifices, des espérances et des résultats féconds des époques antérieures. Cette continuité dans le temps, arrièreplan d'une réalité supérieure, donne la mesure des grands peuples ${ }^{72}$.

72. Roger Duhamel, * Profils d'épopée », la Relève, vol. 1, n 2, p. 23. 
Dans cette perspective, on comprendra que l'œuvre nationalisante de Groulx ait été appréciée par les rédacteurs de la Relève. Jean Chapdelaine dira que son 《histoire est une école de fierté et de patriotisme ${ }^{73}$ », qu'en l'écrivant, Groulx a contribué plus que tout autre à secouer l'apathie des Canadiens français. On ne peut pas dire cependant que, dans l'ensemble, les rédacteurs de la Relève adoptèrent jusqu'à sa conséquence dernière la conception de l'histoire de Groulx, qui débouchait sur l'urgence de créer un État français. Chapdelaine, dans son article, enflammé par la lecture de Groulx, a beau écrire «notre place n'est pas à Ottawa, notre place n'est pas dans l'Ouest, colonisé avec notre argent pourtant. Notre place, c'est Québec », il ne sera guère suivi dans cette voie-là par les autres rédacteurs de la Relève. La revue, c'est une autre de ses caractéristiques, n'aura jamais de politique constitutionnelle bien précise. Elle ne sera ni franchement fédéraliste ni franchement nationaliste. Elle se balancera entre les deux positions et se souciera peu de se brancher. En ce sens, sa lecture de Groulx ne l'aura guère influencée. Il est d'ailleurs significatif que, à l'exception de quelques brèves chroniques de Duhamel et de Frégault, la revue n'ait guère publié de textes sur l'histoire québécoise, et ce en dépit de la profession de foi de Duhamel. C'est que ce n'était pas dans cette histoire-là qu'elle cherchait un modèle pour la société qu'elle désirait construire. Ce modèle, elle allait le trouver dans la société européenne du Moyen Âge.

En ce sens, on peut dire que la conception de l'histoire de Maritain a eu sur les rédacteurs de la Relève une influence beaucoup plus forte que celle de l'abbé Groulx. Chez Maritain, l'histoire est régie par des principes. C'est ainsi qu'au Moyen Âge l'organisation de la société s'appuie sur un humanisme théocentrique qui «reconnaît que Dieu est le centre de l'homme», qui «implique la conception chrétienne de l'homme pécheur et racheté, et la conception chrétienne de la grâce et de la liberté ${ }^{74}$ ». L'époque moderne, au contraire, s'appuie sur une conception anthropocentrique de l'homme, fait de l'homme le centre de toutes choses. L'histoire prend donc un autre cours à partir du moment où la conception anthropocentrique de l'humanisme a remplacé la conception théocentrique, soit à l'époque de la Renaissance. Pour Maritain, il ne faisait aucun doute que la société du Moyen Âge était infiniment supérieure à la nôtre. Et Daniel-Rops écrira, pour sa part : "Entre une société comme la nôtre qui n'a pas encore trouvé d'ultima ratio autre que la force, et celle où l'on demandait

73. Jean Chapdelaine, « l'Abbé Groulx », la Relève, vol. 1, no 4, p. 81.

74. Jacques Maritain, op. cit., p. 35. 
conseil à un moine, parce que c'était un saint, la différence n'est sans doute pas à notre honneur ${ }^{75}$. 》 D'où la volonté d'établir un «nouveau Moyen Âge ».

Toute l'histoire de l'humanité sera jaugée à l'aune du Moyen Âge, décrit comme l'âge d'or de l'humanité, l'âge où s'est réalisée de façon harmonieuse la liaison du temporel et du spirituel.

Ainsi l'époque connue sous le nom de Miracle grec, époque de «plénitude de la raison et splendeur de la lumière intellectuelle purement humaine », n'en a pas moins finalement abouti au «syncrétisme religieux le plus désordonné... parce qu'il manquait à l'intelligence l'appui ontologique du Dieu personnel révélé ${ }^{76} \gg$.

La Renaissance, période de créativité intense, n'en a pas moins «donné lieu à notre déplorable civilisation pragmatique $» . .$. «pour avoir méconnu dans ses principes la primauté du spirituel » et pour avoir prôné le «primat du faire sur l'être ${ }^{77}$ ». Dans un autre texte, Jean-Marie Parent écrira : "La Renaissance fut fatale aux personnes humaines, au destin de l'homme qui est de se réaliser intégralement et librement, par-delà les exigences du siècle, dans la révolution permanente ${ }^{78}$. $\gg$ Révolution permanente qui est bien sûr la révolution sur soi, qui s'accomplit dans l'amour de Dieu sous la direction de l'Église. Abandonné à lui-même, l'homme de la Renaissance devait faillir à la tâche de se réaliser intégralement. Parent prétendra méme qu'à la Renaissance aucun grand artiste "ne put atteindre son maximum - même Michel-Ange ». Ainsi, l'art même de la Renaissance est évalué par rapport à celui du Moyen Âge défini comme le meilleur art qui ait jamais existé. Nous reviendrons là-dessus. Allant encore plus loin, les rédacteurs de la Relève écriront, à la suite de Berdiaev, que «toute grandeur authentique de la Renaissance a un lien avec le Moyen Âge chrétien ${ }^{79}$. » Autrement dit, la Renaissance n'a aucune grandeur authentique, elle n'a rien produit de bon. Les quelques rares grandes réalisations qu'elle a accomplies ne lui appartiennent pas en propre mais sont le fruit de ce qui survivait en elle du Moyen Âge.

p. 610 .

75. Daniel-Rops, "Saint Bernard et son message `, la Nouvelle Relève, vol. 4, no 7,

76. Jean LeMoyne, "l'Intelligence et le monde incarné ^, la Nouvelle Relève, vol. 5, no 4, p. 105 .

77. Ibid.

p. 222 .

78. Jean-Marie Parent, Victimes du destin d'une époque », la Relève, vol. 3 , no 8 , 79. La Relève, «Un nouveau Moyen Âge », p. 210. 


\section{VOIX ET IMAGES DU PAYS $V$}

Le xixe siècle n'est guère plus prisé. Il est d'ailleurs vu comme un des fruits de l'individualisme qui s'imposa à partir de la Renaissance. Avec son positivisme, son matérialisme, il est considéré comme le siècle antispiritualiste par excellence. Mounier écrira : «On a dit que le dix-neuvième siècle était stupide, ce qui était sans doute injuste, alors qu'il fut peut-être pire : médiocre ${ }^{80}$.

Le $\mathrm{XX}^{\mathrm{e}}$ siècle, par comparaison avec le $\mathrm{XIX}^{\mathrm{e}}$, sera considéré comme « un siècle de grandeur ${ }^{81} \gg$. Pourquoi ? Parce qu'il marque la fin d'une époque, celle commencée à la Renaissance. Bien sûr, le monde actuel est pourri. Et les rédacteurs de la Relève le rejettent carrément. Mais justement, il est tellement pourri qu'il ne peut plus durer : il appelle un changement radical. Et, en ce sens, il est riche de possibilités. Si l'humanité sait les exploiter, ce siècle peut être l'aube d'une nouvelle civilisation.

Dans un texte intitulé «Rupture », Robert Élie, étudiant notre histoire dans cette perspective, en arrivera à la conclusion que celle-ci suit une courbe descendante. À partir du régime français, la situation de la société québécoise, selon lui, n'a cessé de se dégrader. Sous le régime français, il y avait une union profonde du spirituel et du temporel : «L'Église avait voix aux conseils et la justice se rendait selon son esprit ${ }^{82}$. $\gg$ Par la suite, après la Conquête, cette union allait être brisée: la collaboration de l'Église et de l'État n'allait plus être qu'intermittente et progressivement le temporel allait acquérir une autonomie de plus en plus grande par rapport au spirituel. Pour notre peuple, cette rupture fut un grand malheur et le désarroi actuel en témoigne. À ce malheur, il n'est qu'un remède : «rompre à tout prix pour retrouver le centre du temporel : le Christ, et sa chair : la patrie, pour rayonner du centre à la chair de Celui dont les Noms sont toutes réalités ».

L'histoire donc, malgré l'utilité qu'on s'accorde à lui reconnaître dans la vie d'un peuple, n'est guère utilisée pour éclairer des situations présentes ou comme justification des comportements actuels. Les rédacteurs de la Relève n'y recourront donc pas souvent. Par ailleurs, ceux-ci voient de la façon suivante le déroulement de l'histoire : l'humanité, des origines au Moyen Âge, n'a cessé de progresser, a connu un âge d'or, puis s'est engagé, à partir de la Renaissance, sur une voie sans issue. L'histoire comporte donc, pour eux, trois grandes phases : l'avant Moyen Âge, le Moyen Âge et l'après Moyen Âge. La période durant

80. Emmanuel Mounier, «Lettre de France», p. 102.

81. Ibid.

82. Robert Elie, "Rupture », la Relève, vol. 2, no 6, p. 172-177. 
laquelle l'humanité a pu se développer le plus intégralement a été le Moyen Âge. Il importe donc de créer, en ce siècle de convulsion, un nouveau Moyen Âge qui conserve, en les adaptant, les principes essentiels sur lesquels reposait le premier Moyen Âge. En ce sens, en tant que le Moyen Âge fournissait aux rédacteurs de la Relève un modèle de société à créer, on peut dire que l'histoire a été pour eux, selon l'expression de Fernand Dumont, «technique d'action». Mais seulement en ce sens très général.

\section{E. L'art, la littérature}

Plusieurs d'entre eux étant écrivains, on ne se surprendra pas d'apprendre que les rédacteurs de la Relève ont consacré une large part de leurs réflexions aux problèmes de la création artistique et littéraire. À l'endroit de l'art, les rédacteurs de la Relève auront une attitude ambivalente, pour ne pas dire contradictoire. D'une part, ils considéreront que l'art a sa fin en lui-même, qu'il ne renvoie à rien d'autre qu'à lui-même, d'autre part, ils lieront le sort de l'art au problème plus large de la civilisation et auront tendance à le subordonner aux valeurs spirituelles de la même façon qu'ils subordonnaient le temporel au spirituel. Voyons à l'aide de quelques exemples comment le problème se posait pour eux.

Précisons au départ que pour les rédacteurs de la Relève, à l'exception de l'art de quelques artistes, dont Claudel, Mauriac, Bernanos, pour nommer ceux le plus souvent mentionnés, l'art contemporain était le meilleur témoignage de la crise dans laquelle se trouvait l'humanité. Plaidant pour une nouvelle forme d'expression et de culture, Jean-Marie Parent constatera amèrement :

Le pius péremptoire témoignage de notre carence morale à nous, et de notre désaxement spirituel est bien l'aspect présent de la littérature moderne, et aussi la position où est tenue la culture. Qui voudra, au crépuscule de notre agonie, approfondir la misère de nos âmes à nous, humains de 1937, n'aura qu'à analyser la montée désordonnée et fébrile de l'histoire littéraire et culturelle de notre siècle ${ }^{83}$.

La Crise est aussi dans l'art. Robert Élie écrira pour sa part : «Cet anéantissement, cette perte du sens de l'être, cette disparition du souci métaphysique et spirituel se manifeste plus absolu et plus inquiétant dans le procès de la poésie,

83. Jean-Marie Parent «Vers une nouvelle forme d'expression et de culture », la Relève, vol. $3, \mathrm{n}^{\mathrm{0}} 7$, p. 181 . 
et même, de l'art ${ }^{84}$. $\gg$ Pourquoi l'art moderne est-il ainsi condamné ? C'est qu'il a oublié la véritable hiérarchie des valeurs et, pour autant, souffre lui-même d'un manque d'harmonie. Or, "l'art est harmonie, il est vérité ordonnée parfaitement ${ }^{85}$ ». L'art véritable est révélation du côté divin des choses, est manifestation de la vérité :

La réalité artistique, si vraiment elle est telle, est une création aussi belle qu'elle est vivante. Mais vivante de quoi ? d'une pensée universelle, qui est un reflet de la pensée divine : l'homme la cueille et la réalise par ses propres moyens; et ainsi chaque œuvre d'art est une révélation de la vérité ${ }^{86}$.

Dans le même ordre d'idées, Jacques Leduc définira la poésie : «Une extase devant l'unité de la Création ${ }^{87}{ }$, et voudra la mettre au service de ce qu'il appelle l'utilitarisme spirituel : «Le poète sera utilitaire, par essence : mais divinement, comme les saints mettent à profit toute seconde et tout événement : Il extraira, jusqu'à la dernière goutte, le spirituel des créatures. Il prouvera le spirituel ${ }^{88}$.

L'art, en somme, doit favoriser la révolution spirituelle dont notre temps a besoin, contribuer à l'élévation de l'homme. Et pour cela, il devra lui-même être spiritualiste. "Dans la grande révolution qui s'ébauche et qui devra être le retour de l'humanité au spirituel, écrit Saint-Denys Garneau, il s'impose que l'art, cette couronne de l'homme, l'expression suprême de son âme et de sa volonté, retrouve son sens perdu et soit l'expression splendide de cet élan vers le haut ${ }^{89}$. $\gg$ L'art est ainsi subordonné à une tâche qui le dépasse et en même temps lui donne son sens. C'est dans la mesure où il contribuera à redonner leur place aux valeurs spirituelles qu'il sera grand. Et, inversement, moins l'art fera de place aux valeurs spirituelles, moins grand il sera. C'est ainsi que le surréalisme sera condamné parce qu' «il place l'instinct au-dessus de la raison, il élève la matière au-dessus de l'esprit, il s'affirme comme une négation de l'âme immortelle, créée à l'image et à la ressemblance de Dieu ${ }^{90} \gg$. Le critère d'appréciation

84. Robert Élie, le Sens poétique », la Relève, vol. 1 , no 8, p. 205.

p. 40 .

85. Hector de Saint-Denys Garneau, l'Art spiritualiste », la Relève, vol. 1, no 3, no 4 , p. 213. p. 111 .

86. Luigi Sturzo, la Poésie dans la Divine comédie `, la Nouvelle Relève, vol. 3, 87. Jacques Leduc, «ette momie, le Parnasse français `, la Relève, vol. 3, no 4,

88. Ibid., p. 112.

89. Saint-Denys Garneau, op. cit., p. 43.

90. Henri Girard, « la Peinture surréaliste », la Nouvelle Relève, vol. 6, no 5, p. 424. 
pour juger de la valeur d'une œuvre d'art est donc son plus ou moins grand degré de proximité des valeurs spirituelles et non ses qualités plus proprement formelles. Dans le cas du surréalisme, Girard, l'auteur du jugement que nous venons de citer, reconnaît que le surréalisme possède des qualités mais malheureusement, celles-ci «tiennent uniquement de la facture ». De même, le Parnasse français et de façon plus générale toutes les doctrines de l'art pour l'art seront-ils condamnés. Pour Saint-Denys Garneau, «les théories funestes de l'art pour l'art qui ressortent du prétendu réalisme et naturalisme sont la plaie mortelle de l'art contemporain ${ }^{91} \gg$. Et le naturalisme lui-même sera condamné par Henri Ghéon pour avoir trop mis l'accent sur « les impulsions de la chair ${ }^{92}{ }^{\text {». }}$

$\mathrm{Du}$ fait que ces conceptions de la littérature furent rejetées au nom d'une conception différente, on ne doit pas tirer la conclusion que les rédacteurs de la Relève avaient une conception étroitement moralisatrice de l'art. Bien au contraire, loin d'être une attitude de refus, leur attitude première à l'égard des expériences artistiques en était une d'accueil. Ainsi LeMoyne, dans un article sur les frères Marx, sera rien moins que tendre à l'endroit de la censure, «cet avorton de la critique, toujours incapable de juger une œuvre d'art en ellemême puisque son jugement porte généralement ailleurs, c'est-à-dire à côté de l'essentiel ${ }^{93}$ ». Et Charbonneau, dans une note sur Gide publiée dans la Nouvelle Relève, écrira, en réponse à deux religieux qui lui avaient reproché d'avoir parlé de Gide dans sa revue, que ce qui l'a toujours guidé dans ses critiques, c'est " une compréhension sympathique, le désir de découvrir non pas ce qu'une œuvre comporte de déficiences ou d'obscurité mais ce qu'elle apporte de révélations sur l'homme, de clartés, de leçons ${ }^{94}$ ». Aussi bien, si les rédacteurs de la Relève opposeront un refus catégorique à certaines conceptions de la littérature, comme nous l'avons vu plus haut, ils demeureront toujours accueillants lorsqu'il s'agira d'étudier une œuvre particulière, même lorsque celle-ci renverra à une théorie qu'ils désapprouvent par ailleurs.

Le fait pour un artiste d'être catholique implique-t-il qu'il est condamné à ne produire que des œuvres à fin «édifiante »? Que certains sujets pour lui sont tabou? Les rédacteurs de la Relève ne le pensent pas. \&Il n'y a pas de zones défendues ou de zones commandées pour l'artiste chrétien, écrit Jean C.

91. Saint-Denys Garneau, op. cit., p. 40.

p. 165 .

92. Claude Hurtubise, «Un entretien avec Henri Ghéon », la Relève, vol. 4, no 6,

93. Jean LeMoyne, « les Frères Marx », la Nouvelle Relève, vol. 5, no 6, p. 188.

94. Robert Charbonneau, "Note sur Gide », la Nouvelle Relève, vol. 1, no 4, p. 193. 


\section{VOIX ET IMAGES DU PAYS $\mathrm{V}$}

de Menasce. Il a droit au cinéma, au ballet, au roman, à l'architecture, il a droit à tous les sujets... L'artiste a même le droit de descendre dans les abîmes à condition qu'il n'y ait pas en lui de complaisance et de connivence ${ }^{95}$. 》 Cependant, précisera Daniel-Rops, le romancier chrétien, par exemple, a toutefois à l'égard de ses personnages un devoir de pudeur et de charité. Aussi doit-il "ménager dans chacun de [ses] personnages, même le plus horrible et le plus abandonné, assez de réserve intérieure pour que la toute puissante charité y puisse poser la main du pardon ${ }^{96}$ ». Le romancier chrétien, à la différence du romancier qui ne l'est pas, ajoutera pour sa part Charbonneau, ne peut se borner à étudier ses personnages sous le seul angle de la psychologie comme le fait généralement ce dernier mais doit toujours se demander à propos de chacun de ses personnages si «celui-là sera sauvé ou si les ténèbres éternelles le happeront. La grande, la terrible difficulté du romancier chrétien est donc de maintenir en équilibre les nécessités rigoureuses de la psychologie et ces nécessités plus graves que multiplie la vision chrétienne de l'homme et du monde ${ }^{97} \gg$.

Cette conception spiritualisante de la littérature allait être mise en forme dans les œuvres de Saint-Denys Garneau, de Robert Charbonneau et de Robert Élie. Nous n'avons pas l'intention d'analyser ici les œuvres de chacun de ces auteurs. Ce qui serait trop long et déborderait, dans une certaine mesure, l'objet de notre étude. Aussi nous contenterons-nous d'émettre quelques remarques sur les œuvres romanesques de Robert Charbonneau et de Robert Élie.

Le professeur Jean-Charles Falardeau qui a étudié l'œuvre de Charbonneau a décrit ainsi son univers romanesque :

Le héros est un rêveur. Néanmoins, il souffre et ses dilemmes l'écartèlent entre deux pôles qu'il perçoit comme inconciliables : d'une part, la vision d'un absolu qui exige holocauste ou renoncement total ; d'autre part, l'action dans un monde extérieur qui est défini comme malsain ou néfaste. La solution est de mourir au monde par fidélité à l'absolu, sinon de rester prisonnier du dilemme. La vie est tension entre le rêve d'absolu et la réalité contaminatrice. Les tentations d'action sont déprimantes ou illusoires. Il faut, à chaque étape, recommencer. La seule activité continue qui demeure possible est l'acte d'écrire - non pas posséder les choses ni le monde, mais les nommer pour en parler : parler de la situation onirique et cruci-

95. Jean C. de Menasce, «Variations sur un thème, le Christ et l'artiste », la Relève, vol. $5, \mathrm{n}^{\circ} 2$, p. 204-205.

96. Daniel-Rops, « le Romancier chrétien ", la Relève, vol. 2, no 3, p. 73.

97. Robert Charbonneau, "le Romancier chrétien», la Relève, vol. 2, no 3, p. 71. 
fiante de soi par rapport au monde. Les interrogations ne portent que sur soi. Les valeurs sont subjectives et transcendantales. La vision du monde est introspective et spirituelle. Ce monde est un aquarium intérieur dont l'homme adolescent est prisonnier, sans cesse heurtant les parois de verre d'où il ne peut s'échapper ${ }^{98}$.

Cette analyse nous semble très bien rendre compte de la réalité de l'univers romanesque de Charbonneau. Pour notre part, nous avons lu les romans de Charbonneau et ceux de Robert Élie et leur lecture nous a laissé des impressions qui confirment l'analyse du professeur Falardeau. Prenons un des romans de Charbonneau, Fontile par exemple. Ouvrons-le. Qu'y trouve-t-on ? L' « histoire », très simple, peut être résumée en quelques lignes. Le héros, Julien Pollender, est né à Fontile, une petite ville de province dominée par une élite clérico-politique ignorante et bête. Il sera successivement élevé par sa belle-mêre (sa mère étant morte lorsqu'il avait à peine trois ans), une femme autoritaire et sèche, puis par une de ses tantes et par une bonne. Son enfance se déroulera donc sous les jupes des femmes, si on peut dire. Julien, encore très jeune, commettra une faute qui le bourrera de remords jusqu'à la fin de ses jours : il dénoncera, en effet, les pratiques «vicieuses » d'une petite fille, ce qui attirera sur celle-ci un lourd châtiment. Par la suite, Julien demeurera, durant toute son enfance, un garçon timide, solitaire, préoccupé par des scrupules religieux : une conscience malheureuse, dirait Sartre. Il fera ses études collégiales dans un établissement local puis, celles-ci terminées, il se rendra étudier en ville. À Montréal, il se découvre une vocation d'écrivain, fait de la littérature ésotérique, que seuls quelques initiés peuvent apprécier, puis déçu par la littérature et par la ville, il revient à Fontile. Pour sortir de son marasme intérieur, il décide de travailler pour les entreprises de son père, un industriel local, mais cela ne le comble guère. Il ne réussit pas à s'intéresser vraiment au travail et à s'y donner à fond. À Fontile, il fait la connaissance d'une jeune femme, Armande Aquinault, dont il s'éprend follement. Celle-ci mourra avant que leur amour ait été consommé. Et Julien se retrouvera seul avec lui-même. On peut, à la suite de la lecture du roman, faire les remarques suivantes :

1. Le héros du roman est un bourgeois d'une petite ville de province, petite ville de province qui ne nous est guère décrite d'ailleurs, et cela se comprend, car l'action du héros est tout intérieure et n'a pas de prise sur la réalité qui l'entoure.

p. 221-222.

98. Jean-Charles Falardeau, Notre société et son roman, Montréal, HMH, 1967, 
2. Le temps de l'action non plus n'est guère précisé. On sait que celle-ci se déroule pour une bonne part durant la période de la Crise, mais la Crise ellemême n'est guère décrite : elle est à peine évoquée.

3. L'amour du héros pour Armande demeurera platonique : il sera rêvé plus que vécu.

4. Le héros analyse sa vie plus qu'il ne la vit : « je vivais en dehors de la réalité », avouera-t-il lui-même.

5. Enfin, le héros ne parvient pas à rompre avec sa solitude. Il demeure renfermé sur lui-même, imperméable aux autres, incapable d'ébaucher une communication authentique avec autrui. D'une certaine façon, il souffre d'un mal qui s'apparente un peu au «mal du siècle » romantique qui se traduisait, on le sait, par une espèce de vague-à-l'âme mal défini. Le «mal du siècle », prenons l'exemple du René de Chateaubriand, se développait dans le cœur du héros lorsque celui-ci se rendait compte que le monde, limité, fini, mesquin, ne pourrait jamais combler les aspirations infinies de son âme. C'est un peu de cela que souffre Julien Pollender ; ajoutons en plus de cela le fait que dans Fontile, le sentiment de déréliction du héros baigne dans un climat de culpabilité et nous comprendrons tout le tragique de sa condition qui ne pouvait guère donner lieu à autre chose qu'à des conduites d'échec.

Ces remarques, généralisées, pourraient s'appliquer à tous les romans de Charbonneau. Bien sûr, il y aurait lieu, selon le cas, d'apporter des nuances aux propositions que nous venons d'énoncer, mais nous pouvons affirmer qu'elles caractérisent assez bien les univers romanesques de chacun des romans de cet écrivain.

La lecture des romans de Robert Élie nous suggère les mêmes observations. Prenons comme exemple le cas de la Fin des songes. L' « histoire \$ peut être grossièrement « résumée » de la façon suivante. Lorsque débute le récit, Marcel, un traducteur de dépêches dans un journal, qui est marié et père de deux enfants, se rend à la campagne voir un ami, Bernard, qu'il n'a pas rencontré depuis longtemps. S'y rendant, il songe à son amitié qui, depuis quelques années, a diminué en intensité, il revoit dans la caméra du souvenir l'ensemble de sa vie, ses années d'adolescence, ses amours de jeune homme qui ne se sont jamais concrétisées, qui n'ont jamais dépassé le cap du désir, sa rencontre avec Jeanne, sa femme, son amour pour elle qui n'a jamais été bien ardent et qui maintenant se désagrège au fil des jours. Bernard, pour sa part, n'est guère plus heureux 
en ménage. Mais moins introspectif, moins tourné vers la vie intérieure que Marcel, il essaie d'oublier son drame en s'engageant à fond de train dans une vie active fébrile. Il fait de la politique, des affaires. Et cela occupe la plus grande partie de son temps. Avec sa femme, Nicole, il a des relations de camaraderie à défaut d'en avoir de plus profondes. Il s'adapte donc mieux à sa condition que Marcel. La deuxième partie du roman présente le journal de Marcel, qui est le compte rendu d'un échec, le récit d'une longue et pénible introspection d'un personnage incapable de sortir de lui-même, de régler ses problèmes, tiraillé entre son devoir conjugal et sa passion pour une femme, Louise, la sœur de sa propre femme et qui ne trouvera pas d'autre solution que le suicide pour s'en sortir. Comme on le voit, les remarques que nous avons faites plus haut sur Fontile pourraient être reproduites ici presque intégralement.

1. Le temps et l'espace ici encore sont des dimensions intérieures.

2. Le héros n'a pas de prise sur le monde. Il dira lui-même : "J'ai vraiment l'impression de me retrouver parfois en face de la réalité, de n'être jamais dans la réalité ; et cette confrontation est cruelle. »

3. Le héros est un être solitaire qui ne parvient jamais à rompre cette solitude et à engager de véritable échange avec autrui. Il est prisonnier de lui-même et cette prison, on le sait, est la plus cruelle de toutes.

4. Ses amours d'adolescent ont été rêvées plus que vécues. Son amour pour Jeanne n'a jamais été qu'une pâle image de l'amour auquel il aspirait et sa passion pour Louise sera "empêchée » par des scrupules moraux et religieux.

Ainsi, dans l'un et l'autre cas, c'est une même vision du monde qui est mise en forme. Vision du monde fondée, on s'en rappellera, sur la primauté des valeurs spirituelles sur les valeurs temporelles, de la vie contemplative sur la vie active, de la révolution intérieure sur l'action dans le monde. Il n'est donc pas surprenant que les héros de ces romans demeurent refermés sur eux-mêmes, prisonniers d'eux-mêmes, incapables de communiquer avec le monde extérieur, condamnés, selon la belle expression du professeur Falardeau, à naviguer à courant et à contre-courant dans un «aquarium intérieur» dont ils ne peuvent s'échapper. Ainsi donc, la connaissance de la vision du monde des rédacteurs de la Relève nous aide à comprendre leur œuvre romanesque de la même façon qu'à l'inverse, leur œuvre romanesque nous fournit un exemple concret des conséquences pratiques d'une telle vision du monde. De même, nous l'avons vu 
précédemment dans cette section, la «théorie» de la littérature des rédacteurs de la Relève et leur jugement sur les «théories» autres que la leur constituent dans le champ particulier de la littérature, une explicitation de leur vision du monde.

\section{F. Les autres thèmes}

La réflexion des rédacteurs de la Relève porta sur un assez grand nombre de thèmes autres que ceux présentés ci-haut. Cependant, cette réflexion fut beaucoup moins suivie que celle qu'ils consacrèrent aux thèmes principaux. Aussi il ne nous paraît pas nécessaire de nous attarder à analyser leur pensée là-dessus comme nous l'avons fait dans les sections précédentes. Nous nous contenterons de la résumer très brièvement.

La solution corporatiste, nous l'avons vu plus haut, paraissait très séduisante aux rédacteurs de la Relève. Aussi leur attitude à l'égard du fascisme qui s'en réclamait, fut-elle, durant les premières années, faite de compréhension et de sympathie. Nous avons, dans la seconde section de cette partie, cité un passage d'un article de Roger Duhamel dans lequel ce dernier considérait le fascisme avec beaucoup de bienveillance. Cette sympathie sera marquée à nouveau lors des événements d'Éthiopie. Claude Hurtubise, sans justifier l'expédition italienne en Éthiopie, soutiendra cependant qu'il ne fallait pas qu'on se saisisse de ce prétexte pour écraser le fascisme. Car, «il faudrait savoir, écrivait-il, si, à côté d'erreurs doctrinales et pratiques indéniables, tout est à rejeter dans ce régime qui a sauvé l'Italie et dont la disparition jetterait le pays dans le chaos ${ }^{99}{ }^{\gg}$. Le fascisme, de fait, ne sera condamné par les rédacteurs de la revue que lorsque ses tendances autoritaires deviendront trop évidentes et que son côté belliqueux se sera manifesté trop clairement. Cette attitude, rappelons-le, tranche avec celle qu'ils entretenaient à l'égard du communisme qui, dès le début, sera rejeté énergiquement. À l'égard du national-socialisme lui-même, la position de la revue, du moins dans les débuts, sera marquée au coin de la bienveillance. C'est ainsi que Claude Hurtubise pourra écrire en toute sérénité :

Le mouvement national-socialiste n'est pas à condamner dans son but immédiat. Il établit l'autorité là où régnait l'anarchie, il réveille un peuple endormi. Mais pourquoi commet-il tant de fautes? Parce qu'il n'est pas dirigé par une pensée catholique. On ne le dira jamais assez, la vérité ne se trouve que dans le catholicisme, toute œuvre qui veut être humaine doit 99. Claude Hurtubise, * De la révolution spirituelle ", la Relève, vol. 2, no 3, p. 82. 
s'appuyer sur lui. Une autre doctrine n'a de vérité qu'en tant qu'elle s'accorde avec lui ${ }^{100}$.

Le régime national-socialiste est donc tenu en haute estime en tant que régime d'ordre. Et à ce titre, il constitue un modèle à imiter. Malheureusement, cet ordre n'est pas fondé sur le catholicisme et, pour cela, ne peut être approuvé sans réserves. Par la suite, bien sûr, le fascisme allait être condamné, surtout à cause de son aspect totalitaire. La Relève, en effet, éprouvait une méfiance instinctive à l'égard de l'État. Et tout régime, fondé sur la prépondérance de celui-ci, lui paraissait immédiatement suspect. L'État, dans la société, devait se contenter d'être un arbitre et ne devait pas par conséquent exercer de contrôle absolu sur toutes les activités de la société : il devait être à son service plutôt que de l'asservir. Dans la mesure où le fascisme donnait dans ce travers, il était condamnable mais dans cette mesure seulement. Aussi longtemps que la Relève crût qu'il pouvait éviter cet écueil, elle se montra très sympathique à son endroit.

Sachant que la Relève désirait une révolution spirituelle qui soit d'abord une révolution de la personne, on pouvait s'attendre à ce que ses rédacteurs consacrent une part importante de leur réflexion au problème de l'éducation. L'éducation n'était-elle pas le meilleur moyen, le plus efficace, pour créer un homme nouveau ? Or, contrairement à ce à quoi on pouvait s'attendre, les rédacteurs de la Relève se montrèrent très discrets sur ce sujet. Georges Turcot, dans un article ${ }^{101}$ sur l'œuvre de Dom Bosco, montrera bien qu'une école centrale de métiers est nécessaire au Québec si l'on veut former des ouvriers qualifiés, compétents, qui pourront prendre la relève des travailleurs étrangers qui occupent, en raison de leur compétence supérieure à celle de nos ouvriers, une place qui normalement reviendrait à nos travailleurs. La revue publiera même un numéro spécial sur l'enseignement spécialisé dans lequel elle ne fera guère preuve d'originalité. Tous les articles du numéro en question ne constituent qu'une sorte d'inventaire des cours dispensés dans les écoles spécialisées de la province. On n’y retrouve pas d'article de fond ni sur la situation générale du Québec à cet égard ni sur ce qu'il conviendrait de faire pour l'améliorer. On se contente tout simplement de souligner l'importance d'un bon enseignement spécialisé. La revue, de même, ne consacrera aucune analyse sérieuse au système scolaire québécois, à la façon dont l'enseignement est dispensé, à la philosophie qui l'inspire. Sa

100. Claude Hurtubise, "Compassion pour une jeunesse catholique ", la Relève, vol. $1, \mathrm{n}^{\mathrm{o}} 2$, p. 30 .

101. Georges Turcot, "l'CEuvre de Dom Bosco », la Relève, vol. 3, no 7, p. 169. 
contribution, sur la question de l'éducation, se bornera à demander que l' éducation nationale » dans les collèges soit donnée jusqu'à la fin du cours classique et à vanter les mérites du scoutisme comme méthode d'éducation complémentaire. Sur ce plan, le moins qu'on puisse dire, c'est que la réflexion des rédacteurs de la Relève est restée à la surface du problème.

Reprenant à son compte la phrase de Claudel : "On dit que la jeunesse est l'âge du plaisir : ce n'est pas vrai, c'est l'âge de l'héroïsme », la Relève attendra de la jeunesse la régénération du monde actuel. Claude Hurtubise écrira : «La génération qui part, je parle de celle qui est au pouvoir, ne laisse que des ruines, que des inventions saugrenues qui ont fait faillite ${ }^{102}$. $\gg$ De sorte qu'il faut que cette génération décampe, en bloc, emportant tout cela, qui n'est pas une «tradition», et laisse la place aux jeunes. Guy Frégault reprendra la même idée dans un autre article et résumera sa pensée dans la phrase suivante : "Pour tout dire, ces gens [la génération précédente] se sont fait un onzième commandement de vivre en marge du réel. C'est pour cela que seuls des jeunes ont pu prendre conscience du réel; prise de conscience qui ne peut se traduire autrement que par un refuls ${ }^{103}$. $\gg$ Le salut du monde donc réside dans les mains de la jeunesse. Il appartiendra à celle-ci de relever victorieusement le gant. Si elle faillit à sa mission, le monde roulera dans l'abîme. Elle est donc investie d'une lourde responsabilité. On espère qu'elle saura s'en montrer digne. La revue, dans cette perspective, consacrera des articles à des mouvements de jeunes comme la J. O. C., la J. O. C. F., et les Jeune-Canada, pour rendre compte de leurs activités. Ce refus des aînés, en fait, s'inscrivait logiquement dans la ligne de pensée des rédacteurs de la Relève. Dans la mesure où ils condamnaient le monde actuel, ils devaient rejeter ceux qui l'avaient édifié et mettre leur confiance dans la génération montante.

Les rédacteurs de la Relève consacreront aussi plusieurs articles au thème du travail. Le thème sera abordé de deux façons. D'abord, d'une façon générale, on tentera d'en dégager la signification. Ensuite, d'une façon particulière, on s'intéressera au problème de la mécanisation, du machinisme. Le travail, pour un Guy Frégault, est tout à la fois œuvre de charité, moyen pour l'homme de se perfectionner et d'entrer en communication avec ses semblables. Euvre de charité, parce que produisant des biens, il contribue au bien-être général de la société. Moyen pour l'homme de se perfectionner «en ce sens qu'en incrustant

102. Claude Hurtubise, "Compassion pour une jeunesse catholique », p. 29.

103. Guy Frégault, « Lettres », la Relève, vol. 4, no 1, p. 27. 
dans la matière la poésie de l'homme, le travailleur prend plus étroitement conscience de sa réalité personnelle ${ }^{104} \gg$. Moyen d'entrer en communion avec ses semblables car l'homme, dans le travail, rencontre d'autres hommes avec qui il partage la joie d'un même effort créateur. Mais voilà, dans le monde industriel moderne, où le travail a été fragmenté en une multitude d'opérations, où, à toute fin pratique, il ne requiert plus la créativité de l'homme, où celui-ci ne peut plus y trouver une source d'enrichissement, la valeur humaine (et divine) du travail est largement compromise. Et les rédacteurs de la Relève en sont bien conscients. Guy Frégault, dans un article sur le problème du machinisme, rendra le capitalisme responsable de la situation présente. Le capitalisme qui est, selon lui, une "force de désintégration et de dissociation sociale ${ }^{105}$ », a produit le machinisme qui est un résultat de cette désintégration et de cette dissociation préalablement opérées par le capitalisme. Comment affronter le problème du machinisme, comment rendre un sens humain au travail, lui redonner sa créativité ? Frégault là-dessus n'est guère bavard. Il se contente de dire qu'il faudra mettre le machinisme au service de la personne humaine. Retenons donc de la pensée des rédacteurs de la Relève sur ce thème leur souci de redonner au travail, dans le monde nouveau à créer, une place d'honneur car c'est encore, selon eux, dans le travail que l'homme peut le mieux s'épanouir.

La Relève ne consacrera pas beaucoup d'articles à la question du mariage ni à celle, complémentaire, de la famille. À propos de la famille, H.A. Reinhold, dans un article publié dans le numéro sept de la cinquième série de la Nouvelle Relève (on voit que ce problème fut, c'est le moins qu'on puisse dire, une préoccupation très tardive des rédacteurs de la revue) écrira bien que « le grand problème de notre époque est la restauration de nos familles qui sont déjà, ou seront bientôt, anéanties ${ }^{106}$, mais ne propose aucune mesure concrète pour susciter cette restauration de la famille. Dans toute la revue, par ailleurs, on ne retrouvera pas d'autres textes sur la famille. C'est dire que ce thème ne fut pas au centre de sa réflexion. La même remarque vaut d'ailleurs pour le mariage. Celui-ci, selon Jean LeMoyne, ne doit pas être envisagé comme ordonné à une seule fin : la procréation et l'éducation des enfants. Il est une autre fin aussi importante que celle-ci : le perfectionnement des époux dans la communauté conjugale. À ce point de vue, la pensée de LeMoyne était assez progressiste. Elle le sera cepen-

104. Guy Frégault, «le Travail et l'homme *, la Relève, vol. 4, no 3, p. 76.

105. Guy Frégault, Au-delà du machinisme *, la Relève, vol. 4, no 7, p. 206. p. 610 .

106. H.A. Reinhold, "Renouveau liturgique », la Nouvelle Relève, vol. 5, $\mathrm{n}^{\mathrm{*}} 7$, 
dant beaucoup moins sur la question de la régulation des naissances. Selon lui, toutes les «manœuvres contraceptives» sont interdites à l'homme et celui qui y recourt offense Dieu lui-même : "S'il modifie par sa volonté le cours d'un processus biologique voulu par Dieu, l'homme ne pêche pas contre le droit à l'existence d'un être possible, mais contre le droit souverain de Dieu lui-même ${ }^{10 \tau}$. La biologie appartient au royaume de Dieu et l'homme n'a pas le droit de forcer la porte de ce royaume, d'en lever l'interdit.

En terminant cette section, rappelons que la revue, durant ses premières années d'existence, a entretenu à l'endroit de la France un véritable culte. Et on peut presque dire, sans exagérer, qu'elle parla plus, durant toute son existence de la France que du Canada français. Elle s'intéressa aux mouvements d'idées qui se firent jour en France durant les années 1930, aux publications de la France, à la politique de ce pays. Les responsables de la revue, durant la guerre, non seulement ouvrirent leurs colonnes toutes grandes aux écrivains français mais publièrent encore aux Éditions de l'Arbre qu'ils avaient fondées plusieurs dizaines de livres écrits par des écrivains français. Cette idylle s'assombrira cependant à la fin de la guerre, au moment de la libération, lors de discussions orageuses qui auront alors lieu entre Robert Charbonneau et plusieurs écrivains français au sujet du statut de la littérature canadienne-française. Charbonneau, ulcéré par l'attitude de certains écrivains français, brûlera alors ce qu'il n'avait cessé jusque-là d'adorer, décrétera qu'il ne se fait plus rien de valable sur le plan littéraire en France et qu'il faut maintenant se tourner vers les États-Unis pour trouver quelque chose qui en vaille la peine. Mais, redisons-le, cela ne se produisit qu'après la guerre. Si bien qu'on peut affirmer que durant toute son existence, la revue accorda une place privilégiée à tout ce qui était français. À tel point que Guy Frégault prétendra même à un moment, que notre peuple est de nationalité française et par conséquent qu'il ne constitue pas une entité originale distincte de celle de la France. Mais, dans l'ensemble, l'amour des rédacteurs de la Relève pour celle-ci, n'ira pas aussi loin et la position de Frégault demeurera la sienne propre et non celle de la revue.

\section{G. Conclusion provisoire}

La vision du monde des rédacteurs de la Relève, rappelons-le, s'appuyait sur une conception de l'homme en qui l'on distinguait deux dimensions, ou deux 107. Jean LeMoyne, "Sens et fin du mariage », la Relève, vol. 4, no 9, p. 279. 
composantes : l'individu et la personne. L'homme, en tant qu'individu, est ordonné à la cité, au bien commun terrestre, en tant que personne, il a une vocation supra-temporelle à remplir. L'homme doit d'abord se réaliser en tant que personne. Dans l'ordre des valeurs, la personne a donc la primauté sur l'individu car «ce qui se rapporte à l'âme est plus élevé que ce qui concerne le corps ». Mais voilà : le corps a ses exigences, ses besoins. Ceux-ci seront satisfaits par ce que les rédacteurs de la Relève appellent les œuvres actuelles qui comprennent essentiellement la politique, qui est la science de l'organisation sociale, qui a pour objet l'aménagement de la société, et l'économique, qui est la science de l'organisation économique, qui doit pourvoir aux besoins de l'homme. La société, qui a pour fin d'assurer le bien commun temporel, doit être organisée de telle façon que l'accomplissement de la fin supra-temporelle de l'homme : le service de Dieu, et son épanouissement en tant que personne soient facilités. L'aménagement de la société est donc subordonné à une fin qui lui est supérieure; le temporel est ordonné au spirituel, il doit être fécondé par lui et il doit refléter les vertus divines. Il y a chez les rédacteurs de la Relève une vision unitaire du monde, vision unitaire d'un monde qui comporte bien sûr des ordres différents, mais qui sont tous reliés l'un à l'autre hiérarchiquement. C'est ainsi que le vital est subordonné au culturel qui est lui-même subordonné au spirituel. Aussi la vie contemplative, dans l'ordre des valeurs, est-elle plus importante que la vie active. Et cette dernière n'a de valeur que pour autant qu'elle facilite la première. Cette primauté accordée à la vie contemplative, comme on le verra tantôt, aura de très grandes conséquences dans l'analyse des problèmes étudiés par les rédacteurs de la Relève. Dieu, dans la vision du monde des rédacteurs de la revue, est le centre des valeurs. Et le monde, qui est sa création, n'existe qu'en fonction de Lui. Dans la hiérarchie des ordres qui composent le monde, il occupe la première place : dans ce vaste organisme qu'est l'univers, il forme en quelque sorte la tête qui commande aux parties inférieures qui sont à son service. C'est Lui qui assure l'équilibre du monde, un monde stable, immobilisé en quelque sorte hors du temps et de l'espace dans la sphère abstraite et lointaine des principes qui ont leur assise dans l'éternité.

Cette vision du monde influencera directement les analyses que les rédacteurs de la Relève consacreront aux questions les plus diverses. Nous montrerons comment pour chacun des thèmes qui ont été étudiés dans les sections précédentes. Il ne saurait être question cependant de reprendre en détail les analyses déjà effectuées. 
La Crise, pour les rédacteurs de la Relève, était d'abord une crise de civilisation qui se situait au niveau des valeurs. Bien sûr, on ne niait pas la réalité de la crise économique, mais on ne la considérait que comme la manifestation la plus évidente d'une crise beaucoup plus fondamentale. La misère dont souffrait l'humanité était d'abord morale et provenait du fait que l'homme moderne avait oublié la véritable hiérarchie des valeurs. La seule façon de remédier à la Crise consistait donc à redonner à l'homme le sens des valeurs. Lorsque cette révolution fondamentale serait effectuée, la crise économique se réglerait en quelque sorte d'elle-même. Que la Crise ait été d'abord perçue comme phénomène spirituel nous apparaît comme une conséquence de la vision du monde des rédacteurs de la Relève car dans la mesure où cette vision affirmait la primauté des valeurs spirituelles et la subordination du temporel au spirituel, il était fatal que les rédacteurs de la revue se préoccupassent d'abord du sort fait à ces valeurs dans le monde moderne. Aussi bien, leurs préoccupations furent-elles d'abord centrées sur le sort réservé à la personne du fait de la Crise plutôt que sur celui de l'individu, et ainsi s'explique le fait que leur analyse ne porta ni sur la dimension sociale ni sur la dimension économique de la Crise mais sur ses conséquences spirituelles. De même leur option pour une révolution intérieure plutôt que politique trouve-t-elle ainsi son explication.

Les rédacteurs de la Relève refuseront de même le capitalisme et le socialisme en raison du sort réservé à la personne dans ces régimes. Le capitalisme selon eux, fondé sur un individualisme poussé jusqu'à ses dernières conséquences, condamnait la personne à la solitude dans un monde formé d'atomes, de monades abandonnées chacune à leur sort, imperméables les unes aux autres. Le socialisme, au contraire, dissolvait la personne dans le groupe. Dans les deux cas, la personne était diminuée. Or la personne, pour eux, était à la fois un être social et un être possédant son autonomie propre, et qui devait disposer d'un minimum de liberté pour s'épanouir. On comprendra, dans cette perspective, que le personnalisme communautaire de Mounier ait pu les séduire puisqu'il se proposait justement d'établir une forme de société où les deux dimensions de la personne auraient $\mathrm{pu}$ trouver leur compte. C'est donc au nom de la personne que l'on réclamait l'instauration d'un nouvel ordre social.

Le nouvel ordre social, on ne pensait pas qu'il pourrait être établi par une révolution politique. Une révolution politique, pour les rédacteurs de la Relève, ne pouvait pas transformer le monde en profondeur ni changer l'homme. Seule une révolution morale, intérieure, spirituelle pouvait opérer un tel changement. 
Ici, on le voit, la priorité accordée, sur le plan des valeurs, à la vie contemplative sur la vie active a déteint fortement sur la façon d'envisager l'action révolutionnaire. Plutôt que de s'exercer sur le monde pour le transformer, cette action sera canalisée dans le sens d'une réforme de l'individu. On croit et on espère que la réforme de l'individu entraînera celle du monde.

Dans le domaine artistique et littéraire, nous avons vu que les préférences des rédacteurs de la Relève allaient à l'art spiritualiste, qui connut sa période la plus féconde au Moyen Âge. De même, les plus grands artistes de l'époque moderne, pour eux, étaient des hommes comme Claudel, Péguy dont l'œuvre entière était un chant dédié à l'œuvre du Créateur du Monde. Et c'est d'après la place qu'elles accordaient aux valeurs spirituelles que les «théories» artistiques et littéraires étaient jugées. Enfin, l'action romanesque des œuvres des rédacteurs de la Relève se déroule dans un monde intérieur, aux coordonnées temporelles et spatiales floues : les personnages de leurs romans n'ont pas de prise sur la réalité, n'agissent pas dans le monde et sur le monde, ne cessent pas de s'auto-analyser et s'avèrent incapables de briser les parois de leur prison intérieure et d'entrer en communication avec autrui. La dévalorisation du monde et de l'action sur celui-ci impliquée dans la vision des rédacteurs de la Relève devait-elle nécessairement déboucher, dans le domaine de la création littéraire, sur la mise au monde de personnages comme ceux qui nous sont présentés dans les romans de Charbonneau et d'Élie? Sans doute pas forcément mais il est révélateur quand même qu'il en ait été ainsi. Et l'échec des héros de Charbonneau et d'Élie reproduit à sa façon, sur le plan de la création imaginaire, l'échec plus général de la Relève dont l'influence sur la vie politique et économique de la société québécoise aura été, à toute fin pratique, à peu près nulle.

Il faut dire que la réflexion des rédacteurs de la Relève s'est faite en quelque sorte en marge et au-dessus de la société québécoise de l'époque. À cette société, les rédacteurs de la revue ne consacreront aucune analyse le moindrement sérieuse. Leur réflexion sera diluée dans le cadre d'une réflexion beaucoup plus générale sur le monde actuel. Et cette réflexion sera d'abord d'ordre moral. Il est significatif à cet égard que la Relève ne parle jamais des classes sociales : c'est là une réalité qu'elle ne connaît pas et la plus belle preuve en est qu'elle définira le bourgeois, à la suite de Flaubert, par des traits de caractère, comme quelqu'un qui manque d'élévation de pensée, de grandeur, et non pas comme un individu occupant une place déterminée à l'intérieur du processus de production de la société. On ne s'étonnera pas, en l'occurrence, que les rédacteurs de la 
revue n'aient jamais publié leur «Manifeste pour la patrie ». La rédaction d'un tel manifeste exigeait à la fois une analyse de la société québécoise, une définition d'objectifs à poursuivre par cette société et la formulation d'une stratégie permettant de les atteindre. Or, les rédacteurs de la Relève ne réussirent pas à remplir une seule de ces trois conditions.

De même, nous l'avons déjà remarqué, elle ne consacrera aucune analyse en profondeur au phénomène religieux et au système d'éducation québécois. Toujours, ses analyses se situeront très loin de l'actualité. Elle essaiera bien, à un moment, par la création d'une chronique en principe consacrée à l'actualité, de donner un caractère plus concret à sa réflexion, mais elle n'y réussira pas. Celle-ci demeurera toujours aussi abstraite et même le deviendra de plus en plus dans les dernières années, si l'on excepte les inévitables chroniques d'actualité sur la guerre alors en cours.

Comment expliquer que la pensée de ces jeunes gens ait pu atteindre un tel degré de déréalisation? Pour répondre à cette question, il nous faudra interroger l'histoire des années 1930 et examiner la position sociale de ces jeunes gens à l'intérieur de celle-ci. Sans doute alors serons-nous en mesure de fournir quelque hypothèse pouvant rendre compte de la tournure abstraite qu'a prise leur réflexion.

\section{DE L'IDÉOLOGIE À L'HISTOIRE}

Il ne saurait être question, pour conclure, de reconstituer l'histoire des années 1930, entreprise qui risquerait de nous entraîner hors de notre sujet. Cette histoire, dans le cadre de ce travail-ci, ne nous intéresse que dans la mesure où elle peut nous aider à comprendre et à expliquer l'idéologie des rédacteurs de la Relève. Il nous suffira donc ici d'en rappeler les grandes lignes.

En octobre 1929, avait lieu à New York la célèbre chute des cours qui allait influencer de façon décisive toute la vie économique, sociale et politique de la décennie qui allait suivre. Cette chute fut le résultat d'une crise de confiance des spéculateurs américains à l'endroit des entreprises de leur pays. Quarante ans après la Crise, on s'interroge encore sur les raisons de cette perte de confiance subite des spéculateurs américains : il y a là quelque chose de mystérieux qu'on n'a pas encore réussi à élucider de façon définitive. Richard Lewinston ${ }^{108}$, un 233 pages.

108. Richard Lewinston, Histoire de la crise (1929-1934), Paris, Payot, 1934, 
économiste, estime que la Crise doit être attribuée au décalage de plus en plus accentué qui s'établit durant les années de prospérité de l'après-guerre entre la courbe du développement économique et celle de la Bourse, la première connaissant une accélération beaucoup moins rapide que la seconde.

Quoi qu'il en soit, ce qui nous intéresse ici, ce sont les conséquences de cette Crise. Elles furent désastreuses. La consommation générale diminua. La production s'ajusta à la consommation et connut une baisse importante. L'industrie automobile, notamment, diminua ses activités du tiers, ce qui entraîna la faillite de plusieurs industries de petite importance, dépendantes de ces super-industries. $\mathrm{Au}$ total, la fabrication industrielle de produits durables baissa de $70 \%$, celle des produits non durables de $331 / 3 \%$. Par ailleurs, dans l'agriculture, la Crise se présenta sous l'aspect d'une sur-production. Les agriculteurs n'étaient plus capables d'obtenir des prix raisonnables pour leurs produits. Aussi restèrent-ils pris avec des stocks considérables de marchandises qu'ils brûlèrent, en grandes quantités, pour faire monter les prix. C'est ainsi que des quantités astronomiques de blé, de riz, de café, de sucre furent détruites cependant qu'une partie de l'humanité mourait de faim. Les agriculteurs, en très grand nombre, ruinés par la Crise, vinrent se réfugier dans les villes où ils contribuèrent à grossir le nombre des chômeurs. La masse des salaires qui était de 45 milliards de dollars en 1929 n'était plus que de 25 milliards en 1932. Le produit national brut, pour sa part, qui représentait une valeur de 104 milliards en 1929 ne valait plus que 58 milliards en 1932. L'activité économique tournait donc au ralenti, c'est le moins qu'on puisse dire.

Le chômage, du fait du ralentissement de l'activité économique, connut une hausse inquiétante. Et comme les chômeurs, n'ayant pas d'argent, ne consomment guère, des industries comme le vêtement, la chaussure, éprouvèrent à leur tour des difficultés très sérieuses. La société tout entière fut donc secouée par la Crise et une agitation sociale dangereuse pour l'ordre établi se développa durant quelques années. John Steinbeck nous en a laissé un témoignage saisissant dans des romans comme les Raisins de la colère, En un combat douteux, etc. Le communisme américain connut son âge d'or et, si la Crise ne s'était résorbée peu à peu, sans doute serait-il devenu une force importante dans ce pays.

En 1931, Roosevelt parvient au pouvoir. Le New Deal commence. La remontée sera progressive mais sûre. En 1934, la Crise aux Etats-Unis, si elle n'est pas encore un mauvais moment parmi d'autres à oublier, n'en est pas moins 
jugulée : l'industrie de la construction reprend ses activités sur une haute échelle, celle du fer et de l'acier repart sur un bon pied, la production automobile augmente de $30 \%$ par rapport à l'année précédente, le chômage diminue du tiers. Ce n'est pas encore la prospérité. Mais la situation est meilleure et l'avenir peut être envisagé avec confiance.

Des États-Unis, la Crise se déplace en Europe où elle frappe successivement l'Autriche, l'Allemagne, la Pologne, la France, l'Angleterre, etc. Le chômage et la misère deviennent des problèmes d'envergure internationale. Certains pays sont frappés plus durement que d'autres. L'Allemagne, entre autres, qui demandera à un Hitler de la tirer du pétrin. La France, par contre, sera moins touchée mais n'en connaîtra pas moins des troubles sociaux très sérieux. Aucun pays, à vrai dire, ne sera totalement épargné.

Voisin immédiat des États-Unis, le Canada sera l'un des pays les plus directement affectés par la Crise.

Lorsque, à la façon d'un cyclone, elle s'abat sur le Québec, la province, rappelons-le, car cela constitue une donnée essentielle de la situation, n'est plus une province agricole. En 1931, on ne compte plus que 225 agriculteurs par 1000 travailleurs alors qu'en 1871, selon Hughes ${ }^{109}$, on n'en comptait pas moins de 471. La population active se répartit comme suit : $27 \%$ d'agriculteurs, $36.7 \%$ de travailleurs industriels, $36.3 \%$ de travailleurs répartis dans les activités commerciales et les services. C'est donc en tant que société industrielle et urbaine que la province de Québec sera affectée par la Crise.

Dès 1930, la Crise fait sentir ses effets. Les industries forestières et minières réduisent leurs activités, diminuent à la fois leur main-d'œuvre et les salaires qu'elles lui paient. En agriculture, les prix baissent et la condition de l'agriculteur, dans un grand nombre de cas, devient intolérable. C'est par milliers que ceux-ci désertent la terre et viennent s'établir à la ville où le chômage les attend. Jean Hulliger écrit quelque part dans sa thèse sur l'enseignement social des évêques canadiens ${ }^{110}$, qu'on ne compte pas moins de 471000 chômeurs sur 2565000 travailleurs salariés au Canada en 1931. De $7.17 \%$ qu'il était chez les travailleurs syndiqués en 1929, le chômage au Québec passe à $14 \%$ en 1930, à $17.3 \%$ en 1931 et à $26.4 \%$ en 1932 . Et le chômage total était sans doute

109. Everett C. Hughes, Rencontre de deux mondes, la Crise d'industrialisation du Canada français, Montréal, Lucien Parizeau, 385 pages.

110. Jean Hulliger, l'Enseignement social des évêques canadiens de 1791 à 1950, Montréal, Fides, "Bibliothèque économique et sociale », 1959, 373 pages. 
plus important puisqu'on sait que les travailleurs syndiqués sont dans l'ensemble toujours mieux protégés que les autres. En 1932, 100000 personnes vivaient des secours directs à Montréal. Et Hulliger, toujours, écrit qu'en avril 1933, 513738 personnes vivaient d'allocations de chômage au Québec.

La misère, au début des années 1930, était donc généralement répandue au Québec. Comment elle fut vécue, éprouvée concrètement par les gens de l'époque, on dispose malheureusement de trop peu de témoignages pour le savoir vraiment. Rumilly, dans son tome de l'Histoire de la province de Québec consacré à ces années, nous laisse cependant pressentir ce qu'a pu être cette misère lorsqu'il rapporte un avis public, publié par la ville de Port-Alfred, alors aux prises avec une situation économique intenable :

Avis public est donné à toutes les personnes résidant dans les limites de la ville de Port-Alfred qu'après le 15 avril 1931, il ne restera plus au Conseil de Ville de Port-Alfred aucun moyen d'aucune sorte d'aider aucune personne, ni avec l'argent du chômage, ni avec l'argent du secours direct.

Le présent avis est une suggestion pour que tous et chacun fassent l'impossible pour se procurer de l'emploi en dehors de la Ville, parce que pour un temps illimité il ne semble y avoir aucune possibilité de gagner l'argent nécessaire à la subsistance dans Port-Alfred ${ }^{111}$.

Ce cas ne dut pas être unique. Le chômage et la misère au Québec ne donnèrent pas lieu à une agitation sociale très intense. Les communistes qui étaient très peu nombreux dans la province ${ }^{112}$, et encore en majorité de langue anglaise, ne réussirent pas à transformer cette misère en instrument politique. L'élite traditionnelle du Canada français consacra à la Crise une partie de sa réflexion et proposa quelques réformes dont nous reparlerons tantôt. Le peuple, quant à lui, semble-t-il, la subit avec résignation : du moins, elle ne donna lieu ni à un éveil politique en profondeur des classes populaires, ni à des accès de révolte tels que l'histoire ait jugé bon de les enregistrer.

Lorsque la Crise débute en 1930, Bennett est au pouvoir à Ottawa. Pour mettre fin à la Crise, Bennett recourt à certains moyens qui, selon lui, devraient

111. Robert Rumilly, Histoire de la province de Québec, tome XXXII, la Dépression, Montréal, Fides, 1959, 262 pages.

112. Sur le mouvement communiste au Québec durant les années 1930, voir : Marcel Fournier, * Histoire et idéologie du groupe canadien-français du parti communiste (1925$1945) \star$, Socialisme 69, janvier-mars 1969 , p. 63-78. 
ramener la situation à la normale à brève échéance : aide aux cultivateurs de l'Ouest, programme de travaux publics, aide aux chômeurs, protections douanières, etc. Malheureusement, ces initiatives, quoique nécessaires, ne réussirent pas à normaliser la situation et la misère continua à être générale. En 1935, Bennett décide de «mettre le paquet» et propose un programme complet de réformes sociales et économiques audacieuses dont, entre autres, la réduction de la journée de travail à huit heures, la réduction de la semaine de travail à quarante-huit heures, l'établissement d'un salaire minimum, d'assurances sociales, la création d'un service national de placement, d'une commission sur le commerce et l'industrie pour contrôler les monopoles, d'un office du blé, d'un conseil économique national. Ce programme cependant ne sera pas totalement appliqué. En 1935, les libéraux prendront le pouvoir et rejetteront certaines lois proposées par Bennett, jugeant qu'elles étaient inconstitutionnelles. Ajoutons, avant de revenir au Québec, que l'autre fait marquant de la vie politique fédérale de ces années fut la création, en 1932, du parti C. C. F. Celui-ci, qui sera condamné par l'Église du Québec par la bouche de l'archevêque de Montréal, Mgr Gauthier, sous le prétexte qu'il offrait, selon les dires du prélat, "une forme de socialisme qui ne mérite pas l'adhésion des catholiques ${ }^{113}{ }$, n'aura guère d'influence sur la vie politique de cette période au Québec.

Au Québec, au début des années 1930, les libéraux, dirigés par Alexandre Taschereau, sont au pouvoir. L'opposition est alors formée par les conservateurs, dirigés par Camilien Houde. Ce dernier, en 1932, sera remplacé à la direction du parti par Maurice Duplessis. En 1934, Paul Gouin crée l'Action libérale nationale et entreprend une croisade, avec René Chaloult, Philippe Hamel, contre la «dictature économique » qui, selon lui, règne sur la province, et est responsable de la Crise. Quelle solution propose-t-il pour remédier à la Crise ? La colonisation : "Nous croyons fermement comme beaucoup d'autres, écrit-il dans le manifeste du parti, que l'œuvre de restauration économique se ramène principalement à une œuvre de restauration rurale, basée sur l'agriculture familiale et la coopération ${ }^{114}$.» Cette solution allait aussi être la panacée universelle présentée par tous les penseurs de l'école nationaliste et traditionnaliste du Canada français, comme nous le verrons plus loin. Aux élections de novembre 1934, Gouin et Duplessis unissent leurs forces et viennent bien près de renverser les

113. Rapporté dans Jean Hulliger, op. cit., p. 175.

114. Cité dans l'H'istoire 1534-1968 réalisée par l'équipe du Boréal Express, Montréal, Editions du Renouveau pédagogique, 1968, p. 515. 
libéraux. Le résultat du vote, en effet, se lisait comme suit : 48 libéraux, 24 Action libérale nationale et 16 conservateurs élus. À ce moment, le parti de Gouin est donc plus fort que celui de Duplessis. En 1936, a lieu la célèbre enquête sur les comptes publics. Le gouvernement Taschereau, dans son ensemble, est traîné dans la boue et le premier ministre lui-même juge bon de démissionner. Adélard Godbout le remplace à la tête du gouvernement. En août 1936, de nouvelles élections ont lieu. L'Union nationale, nouveau nom du parti conservateur, bien dirigée par Duplessis, qui a su se rallier la plupart des membres importants de l'Action libérale nationale, remporte les élections haut la main. Les libéraux ne sont plus représentés que par 14 députés et l'Action libérale nationale se retrouve en pleine débandade, n'ayant fait élire aucun député. Un long règne, qui ne sera interrompu que par un bref intermède, commençait pour le plus grand malheur de cette province...

L'élite professionnelle et cléricale canadienne-française, nous l'avons dit plus haut, consacrera une part importante de ses réflexions à la Crise. Cette pensée que l'on retrouve formulée dans des revues comme l'Action nationale, dans les tracts de l'École sociale populaire et dans les actes des Semaines sociales $d u$ Canada, Pierre Elliott Trudeau ${ }^{115}$, qui en a fait l'objet d'une étude fameuse, après avoir fait remarquer que l'axe principal de celle-ci était le nationalisme, a montré que ses promoteurs estimaient que la Crise pourrait être réglée par le recours aux moyens suivants : 1 . le retour à la terre; 2 . le développement de la petite entreprise ; 3 . le développement de la formule coopérative ; 4. l'action du syndicalisme catholique ; 5 . le corporatisme. Le premier point du programme de restauration proposé, il importe de le noter, était le retour à la terre. Nous avons vu tantôt que des hommes politiques aussi en feront l'article premier de leur programme. Ainsi Maxime Raymond, le futur fondateur du Bloc populaire, celui qui ne cessera à Ottawa de dénoncer la «dictature économique », dès 1928, dans un discours prononcé à la Chambre des communes, prétendra que l'agriculture est la base de la vie économique d'un pays et, dans un discours prononcé en 1934, alors que la Crise battait son plein, rappellera que «la campagne fournit l'eau pour rien, le logement, le bois pour se chauffer, l'alimentation, et même en partie les vêtements qui sont des dérivés des produits agricoles transformés. C'est le principal pour la vie. Elle contribue aussi à augmenter le pouvoir d'achat et aide toutes les branches de l'activité économique, qui doivent à l'agriculture

115. Pierre Elliott Trudeau, " la Province de Québec au moment de la grève », dans la Grève de l'amiante, Montréal, Cité libre, 1956. 
la raison même de leur existence ${ }^{116} \gg$. Cette solution du retour à la terre était proposée comme solution pratique, bien sûr, mais de plus était présentée avec tout un appareil de justifications théoriques qui la rendait éminemment souhaitable. Il ne s'agissait pas seulement, par le retour à la terre, de régler un problème économique, il s'agissait de reconstruire une société, la société canadienne-française traditionnelle que la civilisation industrielle et urbaine désintégrait pour son plus grand malheur, croyait-on. Il est significatif d'ailleurs que cette solution ait été proposée par une élite professionnelle et cléricale qui sentait bien que son pouvoir était mis en question dans la société industrielle et urbaine. D'où cette nostalgie d'une société centrée sur la paroisse et dépendante de son élite cléricale et professionnelle (médecin, avocat, notaire). La ville détruisant l'homogénéité de la société canadienne-française, diminuant le pouvoir de son élite professionnelle, réduisant la prépondérance de la paroisse comme centre de vie communautaire, il était normal que cette élite ne la prise guère et lui préférât la paroisse traditionnelle où son prestige et son pouvoir étaient intacts. Un excellent témoignage de l'hostilité de l'élite clérico-politique à l'endroit de la ville et de ses valeurs nous est fourni dans un passage du mémoire présenté par la S. S. J. B. de Montréal à la Commission royale d'enquête sur les relations fédérales-provinciales en 1938 :

La législation ouvrière demeure un palliatif dangereux en accentuant la tendance trop prononcée de tout attendre de l'Etat, et d'autre part, à créer une situation privilégiée aux travailleurs des villes. Dans le premier cas, c'est l'acheminement vers le socialisme d'Etat. Dans le second cas, le contraste ville-campagne, industrie-agriculture accentuera le mouvement de centralisation urbaine. Une législation qui vise à améliorer le sort de l'ouvrier, bonne en soi, ne peut qu'attirer vers la ville le rural. Or, notre population est, par tradition, rurale, et la législation qui peut paraître bonne en d'autres milieux, risque dans notre province de causer des perturbations sociales très grandes ${ }^{117}$.

«Le mouvement de centralisation urbaine», on sent bien que les rédacteurs du mémoire ne l'acceptent qu'à contrecœur. Les témoignages sur cette attitude de l'élite clérico-politique ne manquent pas. Ainsi, les évêques de la province, dans une lettre sur le problème rural au regard de la doctrine sociale de l'Église publiée en 1938 dans un Cahier de l'École sociale populaire ${ }^{118}$ écriront que «l'exode

116. Maxime Raymond, Politique en ligne droite, Montréal, Editions du Mont-Royal, 1943, 240 pages.

117. Cité dans Trudeau, op. cit., p. 40.

118. Lettre des évêques du Québec sur "le Problème rural au regard de la doctrine sociale de l'Eglise », Cahiers de l'Ecole sociale populaire, janvier 1938. 
vers les villes, qui résulte naturellement du souci pour les paysans d'améliorer leur sort, en expose un grand nombre à s'en aller en des milieux nouveaux et mêlés, pour lesquels ils ne sont point préparés, au grand péril de leur esprit chrétien et de leurs mœurs. L'expérience, hélas !, ne le prouve que trop ». Derrière le choix de cette solution du retour à la terre, il y avait donc un choix plus fondamental portant sur ce que devait être la société canadienne-française.

Le refus du monde actuel des rédacteurs de la Relève ne peut être expliqué de la même façon. Bien sûr, les rédacteurs de la revue, par leur origine et par leur formation, appartenaient à la petite et à la moyenne bourgeoisie urbaine canadienne-française. Robert Charbonneau, dans son dernier ouvrage, Chronique de l'âge amer, confesse que la crise économique les avait touchés, lui et ses camarades, "mais d'une façon oblique, surtout en retardant le moment de leur entrée dans le struggle for life ${ }^{119} \gg$. Cependant, l'attitude qu'ils adoptèrent ne peut être qualifiée tout simplement, comme si cela allait de soi et n'exigeait pas plus de précision, d'attitude petite-bourgeoise.

Sartre, dans Questions de méthode, nous met justement en garde contre le « réductionnisme» d'une certaine sociologie qui consiste à dissoudre le particulier dans l'universel, par exemple à prendre l'ouvrage d'un penseur de tendance idéaliste et à ne le considérer que comme une variante de la pensée idéaliste, sans le distinguer des autres variantes, sans dire en quoi il est original par rapport à l'ensemble des ouvrages idéalistes. "Ainsi, écrit Sartre, la réalité concrète d'un ouvrage philosophique, ce sera l'idéalisme ; l'ouvrage n'en représente qu'un mode passager ; ce qui le caractérise en lui-même n'est que déficience et néant ; ce qui fait son être c'est sa réductibilité permanente à la substance idéalisme ${ }^{120}$. 》 Reprenant la même idée quelques paragraphes plus loin, il écrira : "Valéry est un intellectuel petit-bourgeois, cela ne fait pas de doute. Mais tout intellectuel petit-bourgeois n'est pas Valéry. L'insuffisance heuristique du marxisme contemporain tient dans ces deux phrases ${ }^{121}$. $\gg$ Fernand Dumont nous signale le même danger lorsqu'il écrit à propos des idéologies : "Celles-ci ne sont jamais l'expression directe de toute la société, ni même (comme le laissent entendre Marx et, plus confusément, Mannheim) des classes sociales et de leurs conflits ${ }^{122}$. 》

119. Robert Charbonneau, Chronique de l'âge amer, Montréal, Editions du Sablier, 1967, p. 9-10.

120. Jean-Paul Sartre, Questions de méthode, Paris, Gallimard, a Idées », 1967.

121. Ibid., p. 80.

122. Fernand Dumont, « Notes sur l'analyse des idéologies », p. 160-161. 
Ainsi, lorsqu'on dit que l'idéologie qui fut celle des rédacteurs de la revue, était une idéologie petite-bourgeoise, on n'a pas encore dit grand chose. Car elle ne fut pas l' "œuvre» de n'importe laquelle petite bourgeoisie : elle fut celle d'un groupe bien précis à l'intérieur de celle-ci. Un groupe de jeunes gens qui fit des études chez les jésuites, au Collège Sainte-Marie, qui se passionna plus pour les questions artistiques, littéraires et philosophiques que pour les questions financières et boursières, qui n'embrassa pas les carrières traditionnelles des collégiens canadiens-français, soit la prêtrise, la médecine et le droit, ou encore qui ne les embrassa que durant un moment (ainsi Duhamel fera des études en droit mais ne le pratiquera pas), mais fit carrière dans des domaines comme le journalisme, l'édition, la radio. Un groupe donc qui appartenait à l'élite traditionnelle par son origine et sa formation mais qui s'en distingua par les choix qu'il fit parvenu à l'âge adulte.

L'idéologie qu'elle secréta, on l'a vu antérieurement, il était presque fatal qu'elle se distinguât radicalement de celle de l'élite traditionnelle. On a vu précédemment que le modèle de la société nouvelle à créer, les collaborateurs de la Relève ne le prirent pas dans la société traditionnelle canadienne-française, mais dans la société chrétienne féodale du Moyen Âge. Et il est très significatif que les rédacteurs de la Relève n'aient, tout au long de l'existence de leur revue, fait montre d'aucune insistance particulière sur le thème du retour à la terre qui était l'obsession des idéologues de l'élite traditionnelle. Ne s'identifiant pas avec cette élite traditionnelle, les rédacteurs de la Relève ne partagèrent pas leur nostalgie de la société rurale canadienne-française.

Que les rédacteurs de la Relève aient cherché dans le passé le modèle concret de la société nouvelle dont ils désiraient l'instauration ne doit pas nous étonner outre-mesure. Dans une période de crise, les intellectuels ont souvent tendance à se tourner vers le passé dans l'espoir d'y trouver des éléments de solutions à la crise du moment. Ainsi, les hommes de l'époque romantique, qui venaient de vivre la Révolution française, avaient conscience d'être situés à une croisée de chemins. Ils sentaient bien qu'un monde était en train de s'écrouler devant eux, entraînant dans sa chute les belles certitudes sur lesquelles il se fondait. Ils comprenaient que désormais le monde ne pourrait plus être ce qu'il avait été durant de nombreux siècles. Cela déclencha en eux une terrible angoisse. Comment s'étonner, dans ces conditions, que plusieurs d'entre eux se soient tournés vers le passé ? Le passé leur offrait l'image d'une totalité dont le monde en transition dans lequel ils vivaient était privé. Le Moyen Âge, plus particulièrement, 
leur apparut comme le modèle de la société unanime dont ils avaient la nostalgie. Tous les hommes alors partageaient la même vision du monde. La société était dirigée par une aristocratie à deux têtes, dont l'une, la noblesse, se chargeait de l'administration temporelle de la cité tandis que l'autre, l'Église, se chargeait des tâches spirituelles. Ces deux aristocraties s'appuyaient l'une l'autre et partageaient les mêmes valeurs. Leur conception du monde était acceptée par les paysans qui l'avaient intériorisée et faite leur. Les hommes du Moyen Âge avaient le sentiment d'appartenir à un monde harmonieux où une place leur était réservée de toute éternité. L'idéologie régnante leur indiquait la place qu'ils occupaient dans l'univers et les tâches que cela impliquait. Les hommes, en somme, avaient alors une image unitaire et rassurante du monde.

Dans le cas des penseurs romantiques, cette nostalgie, il est vrai, trahissait un désir de retrouver une société dans laquelle ils seraient à nouveau au pouvoir. Car il est remarquable que cette nostalgie du passé ait été surtout le fait des couches aristocratiques de la société de l'époque qui voyaient chaque jour diminuer l'importance de leur pouvoir dans la société nouvelle qui se construisait sous leurs yeux. Les penseurs qui n'appartenaient pas à cette aristocratie auront, au contraire, tendance à proposer des modèles communautaires, pour ne pas dire communistes, de société. Songeons à Fourrier et à sa phalanstère, à Cabet, à Proudhon.

Les rédacteurs de la Relève, comme ceux d'Esprit ou de l'Ordre nouveau en France, étaient à la fois reliés aux élites traditionnelles par leur origine et leur formation et distincts d'elles par leur refus de s'associer à leurs entreprises. Par ailleurs, malgré leur sympathie pour le prolétariat, ils ne purent jamais se confondre avec lui et épouser vraiment sa cause. Leur idéologie sera donc différente de l'une et l'autre de ces classes sociales et elle sera le fruit d'une recherche relativement "désintéressée», dans la mesure où ces jeunes gens n'avaient pas d'intérêts de classe proprement dits à défendre. Que leur idéologie ait été à la fois personnaliste et communautaire nous semble un témoignage éloquent de ceci.

Par ailleurs, l'idéologie de ces jeunes gens, nous l'avons déjà noté, fut on ne peut plus déréalisante : en tant que lecture de la situation, car l'idéologie est d'abord lecture de la situation, elle ne réussit pas à dégager une analyse sérieuse de la société canadienne-française et des problèmes qui la confrontaient alors. Leur analyse se maintint toujours au niveau d'une réflexion théorique sur le monde actuel considéré de façon générale. Il est remarquable, à cet égard, qu'on 
trouve dans la revue très peu de commentaires sur l'actualité politique du Canada français. De sorte que celui qui étudierait l'histoire politique, sociale et économique du Canada français dans la Relève serait fondé de penser qu'il ne s'est strictement rien passé au Canada français durant toutes ces années.

En ce qui concerne la définition des objectifs, les rédacteurs de la Relève ne réussirent pas à formuler d'objectifs concrets susceptibles de déboucher sur une action politique ; le seul objectif qu'ils proposèrent fut un retour au Moyen Âge dont ils ne précisèrent jamais ce que cela signifiait au juste et surtout n'indiquèrent pas les voies pouvant y conduire. À une analyse abstraite de la situation et à une définition large et peu précise des objectifs à atteindre, devait correspondre fatalement une action du même ordre. Et effectivement l'idéologie des rédacteurs de la Relève ne déboucha sur aucune action de transformation radicale de la société et n'exerça aucune influence réelle, du moins dans le domaine social et politique, sur la société canadienne-française.

Nous avons dit antérieurement que cette idéologie devait fatalement être telle dans la mesure où elle s'appuyait sur une vision du monde théocentrique et hiérarchisée, dans laquelle le monde est perçu comme un univers stable, ordonné, formé d'ordres unis organiquement. Nous voudrions ici apporter une nuance à cette affirmation. Il est possible que l'étude de l'idéologie de l'élite traditionnelle nous renvoie à une vision du monde analogue à celle des rédacteurs de la revue. N'oublions pas que les membres des élites traditionnelles ont été formés dans les mêmes collèges que les rédacteurs de la Relève. Or leur idéologie, comme nous l'avons souligné plus haut, est sensiblement différente de celle des rédacteurs de la revue. Comment expliquer cela? On peut, nous croyons, en proposer l'hypothèse suivante : à partir d'une même vision du monde, commune à toute une communauté, ou à tout le moins à une classe - ce n'est pas le moment ici d'ouvrir une discussion théorique, à savoir si la vision du monde doit être rapportée aux classes ou si elle peut être rapportée, dans certains cas, à une communauté dans son entier - , des idéologies diverses peuvent naître de groupes différents à l'intérieur de la communauté ou de la classe considérée. C'est ainsi que l'élite traditionnelle et les jeunes gens de la Relève, partageant une même vision du monde, à supposer que la vision du monde de l'élite traditionnelle ait été la même que celle des rédacteurs de la revue, accouchèrent d'idéologies différentes, la première, fondée sur le désir de conserver une société définie par la tradition, la seconde, fondée sur le désir de créer une société nouvelle, organisée selon les principes de l'ordre social chrétien tel qu'il a existé au Moyen Âge ; cette diffé- 
rence peut, et nous l'avons fait plus haut, être expliquée par leur situation respective à l'intérieur de la structure sociale.

Une étude comme celle-ci permet d'apporter des nuances à certaines affirmations plus générales sur l'évolution des idéologies au Canada français. Ainsi, Marcel Rioux, dans son livre récent, la Question du Québec ${ }^{123}$, prétend que jusqu'en 1939 a prédominé au Québec ce qu'il appelle l'idéologie de conservation, dans laquelle la société canadienne-française est définie comme une culture qui a un héritage à transmettre (religion catholique, langue française, mode de vie rural), idéologie qui, selon lui, prit naissance à la suite des troubles de 18371838. À cette idéologie a succédé, après la guerre, une idéologie de rattrapage, prétend Rioux. En gros, celui-ci a raison, c'est bien certain : une étude comme celle que nous venons de faire de la Relève nous permet cependant de préciser que cette idéologie dominante ne fut pas la seule, qu'à côté d'elle, en marge d'elle, d'autres idéologies furent mises en forme qui proposaient une lecture différente de la situation et des objectifs autres que ceux proposés par l'idéologie dominante. Et la Relève n'en fut qu'une parmi d'autres. Nous sommes persuadés qu'il y en eut d'autres.

Ainsi donc, et nous terminerons là-dessus, revenant en quelque sorte à notre point de départ, l'étude de la Relève nous a montré comment les années 1930 , et en particulier la Crise, ont été perçues et vécues par un groupe bien déterminé à l'intérieur de la population canadienne-française, et par ailleurs, l'analyse malheureusement trop succincte de l'histoire de ces années - mais ce n'était pas là l'objet premier de notre analyse qui consistait d'abord à montrer comment les rédacteurs de la Relève construisirent leur problématique - nous a permis de proposer une hypothèse concernant la genèse de l'idéologie des rédacteurs de la revue. Ainsi, l'histoire et l'idéologie, considérées dans cette perspective, s'éclairent l'une l'autre. Ajoutons que l'hypothèse que nous avons proposée de la genèse de l'idéologie des rédacteurs de la Relève, que nous croyons juste, pour être confirmée de façon définitive, exigerait de longues recherches sur chacun de ses rédacteurs, ce que nous ne pouvons nous permettre dans les cadres de ce travail. Souhaitons que d'autres le fassent de sorte que ce qui n'est ici qu'hypothèse acquierre le statut de certitude.

\section{JACQues Pelletier}

123. Marcel Rioux, la Question du Québec, Paris, Seghers, 1969. 